\title{
Large-scale atmospheric forcing and topographic modification of precipitation rates over High Asia - a neural-network-based approach
}

\author{
L. Gerlitz, O. Conrad, and J. Böhner \\ University of Hamburg, Institute of Geography, Bundesstraße 55, 20146 Hamburg, Germany \\ Correspondence to: L. Gerlitz (lars.gerlitz@uni-hamburg.de)
}

Received: 29 August 2014 - Published in Earth Syst. Dynam. Discuss.: 13 October 2014

Revised: 13 January 2015 - Accepted: 3 February 2015 - Published: 27 February 2015

\begin{abstract}
The heterogeneity of precipitation rates in high-mountain regions is not sufficiently captured by stateof-the-art climate reanalysis products due to their limited spatial resolution. Thus there exists a large gap between the available data sets and the demands of climate impact studies. The presented approach aims to generate spatially high resolution precipitation fields for a target area in central Asia, covering the Tibetan Plateau and the adjacent mountain ranges and lowlands. Based on the assumption that observed local-scale precipitation amounts are triggered by varying large-scale atmospheric situations and modified by local-scale topographic characteristics, the statistical downscaling approach estimates local-scale precipitation rates as a function of large-scale atmospheric conditions, derived from the ERA-Interim reanalysis and high-resolution terrain parameters. Since the relationships of the predictor variables with local-scale observations are rather unknown and highly nonlinear, an artificial neural network (ANN) was utilized for the development of adequate transfer functions. Different ANN architectures were evaluated with regard to their predictive performance.

The final downscaling model was used for the cellwise estimation of monthly precipitation sums, the number of rainy days and the maximum daily precipitation amount with a spatial resolution of $1 \mathrm{~km}^{2}$. The model was found to sufficiently capture the temporal and spatial variations in precipitation rates in the highly structured target area and allows for a detailed analysis of the precipitation distribution. A concluding sensitivity analysis of the ANN model reveals the effect of the atmospheric and topographic predictor variables on the precipitation estimations in the climatically diverse subregions.
\end{abstract}

\section{Introduction}

The large-scale spatial pattern and the seasonal and interannual variability of precipitation rates over central and High Asia has been widely studied, particularly with regard to its impact on downstream hydrological regimes and hence on the climate-sensitive agriculture-dominated economies of the highly populated downstream areas (Akhtar et al., 2008; Mall et al., 2006; Matthews et al., 1997). The main rivers of South and East Asia such as the Indus, Ganges, Brahmaputra, Huang-He and Yangtze have their upper catchment areas on the Tibetan Plateau or in the adjacent mountain regions and are mainly fed by the enhanced precipitation rates compared with the surrounding lowlands and by snow melting in spring. Glacial runoff contributes to a lesser extent but is crucial for the base flow during dry season (Immerzeel and Bierkens, 2010). The glacial dynamics are likewise distinctly influenced by the local- and mesoscale climate variability (Maussion et al., 2014). Particularly for the investigation of the climatic influence on the fragile ecosystems of central and High Asia, spatially high resolution climate data are required. While the temporal and spatial variations in nearsurface temperatures over central and High Asia have been modeled with reliable results (Böhner, 2006; Gerlitz et al., 2014), the accuracy and spatial resolution of available gridded precipitation estimates do not yet satisfy the demands of climate impact studies (Schoof, 2013). Gridded climate reanalysis products, such as ERA-Interim, adequately simu- 
late the large-scale atmospheric features over Asia, but fail to capture the topographic variability of precipitation rates over the highly structured target area. Often reanalysis products are refined by means of dynamical downscaling applications, which employ regional climate models (Maussion et al., 2014). However, due to exponentially increasing computational demands with rising spatial resolution, most studies focus on very limited target domains or time frames. Dynamically downscaled fields for larger regions seldom achieve resolutions below $10 \mathrm{~km}$ and thus still do not address typical boundary layer processes on the meteorological micro- $\beta$ to meso- $\gamma$ scale, such as topographically induced convective systems or local-scale orographic precipitation. In contrast, less computationally demanding statistical downscaling approaches aim to develop empirical transfer functions, linking independent large-scale atmospheric parameters to nearsurface observations in order to predict local-scale climate conditions under altering synoptic situations. Since statistical downscaling applications are usually calibrated based on point-scale observations, they enable the estimation of near-surface climates for specific locations. Although some studies indicate that the preciseness of statistical downscaling applications is comparable with dynamical downscaling approaches (Schoof, 2013), the generation of fully distributed climatic fields by means of statistical techniques still remains challenging (Maraun et al., 2010). Against this background, we present a novel empirical approach which enables an estimation of spatially high resolution monthly precipitation fields, basically merging statistical downscaling of large-scale atmospheric fields and DEM-based terrain parameterization methods. Therefore we consider localscale precipitation as a function of large-scale atmospheric parameters on the one hand and a local-scale terrain-induced modification on the other. Selected terrain parameters were developed and evaluated with regard to their representation of local-scale atmospheric processes, which typically lead to precipitation occurrence. Subsequently statistical relationships between large-scale atmospheric conditions, terrain parameters and local-scale precipitation observations were analyzed and adequate transfer functions were developed. Based on the assumption that the atmosphere-topography interactions are highly nonlinear, we utilized an artificial neural network (ANN) approach for the analysis of the statistical relationships. Neural networks stand out due to their ability to approximate any continuous multidimensional function and their capability to handle the interactions of interconnected predictors. Neural networks have seen increasing use in the field of climate- and geosciences, particularly for the examination of complex systems with unknown relationships between several predictor and predictand variables.

Due to the integration of physically based terrain parameters for the estimation of local-scale precipitation rates, the presented approach remains physically consistent and can be utilized for the development of local-scale climate change scenarios. All methods have been applied on a 64 bit Win- dows personal computer, which reflects the low computational demands of the approach and its suitability for climate and climate impact studies in environmental offices and research units, even in central Asian countries.

In the following section, we firstly provide a brief overview of large-scale circulation modes, associated pluviometric regimes and their topographic modifications over the target area. Subsequently, we introduce the utilized large-scale atmospheric data sets and the derivation of precipitation-relevant terrain parameters in Sect. 3.1. Section 3.2 addresses the implementation and validation of the statistical model. Subsequently, the spatiotemporal variability of precipitation rates over the target area as well as the influence of the major atmospheric and topographic predictors is analyzed in Sect. 3.

\section{Large-scale circulation modes, pluviometric regimes and the role of topography}

The target area, shown in Fig. 1, covers the Tibetan Plateau and the main mountain ranges of High Asia, such as the Himalayan Arc, the Kunlun Shan and the Quilian Shan. The adjacent Indus-Ganges Lowlands, the Tarim Basin and the Red Basin define the borders of our target domain. Extending from 80 to $105^{\circ} \mathrm{E}$ and 25 to $42^{\circ} \mathrm{N}$, the pluviometric regimes of this vast area are controlled by both tropicalsubtropical and extratropical circulation systems. Seasonal shifts in large-scale circulation modes and the associated alternation of air masses lead to a distinct hygric seasonality commonly subsumed under the term "monsoon". Although this characteristic differentiation between a rather moist summer and a dry winter season is valid for most of the target area, precipitation regimes and their spatial domains differ in terms of air masses and involved synoptic processes. In general, the target area is controlled by three major pluviometric regimes: the East Asian summer monsoon, the South Asian summer monsoon (synonymous with the Indian summer monsoon) and the extratropical westerlies and their associated fronts and disturbances (Böhner, 2006; Maussion et al., 2014).

In summer the continental areas of the target area and especially the elevated Tibetan Plateau act as a heat source, which triggers the development of the autochthonous "plateau monsoon", a shallow direct circulation mode converging above the Tibetan Plateau (Flohn, 1987). Enhanced flux of sensible heat from the elevated heat source and the release of latent heat in high-reaching convection clusters over the northeastern Indian plains and adjacent mountain ranges lead to the formation of a warm anticyclone in the mid- to upper troposphere (monsoon high) and establishes the $500-200 \mathrm{hPa}$ layer over southern Tibet as the Earth's free-atmosphere warm pole. The resulting reversal of uppertroposphere temperature gradients in the Indian-Indonesian sector forces the development of the Tropical Easterly Jet, 


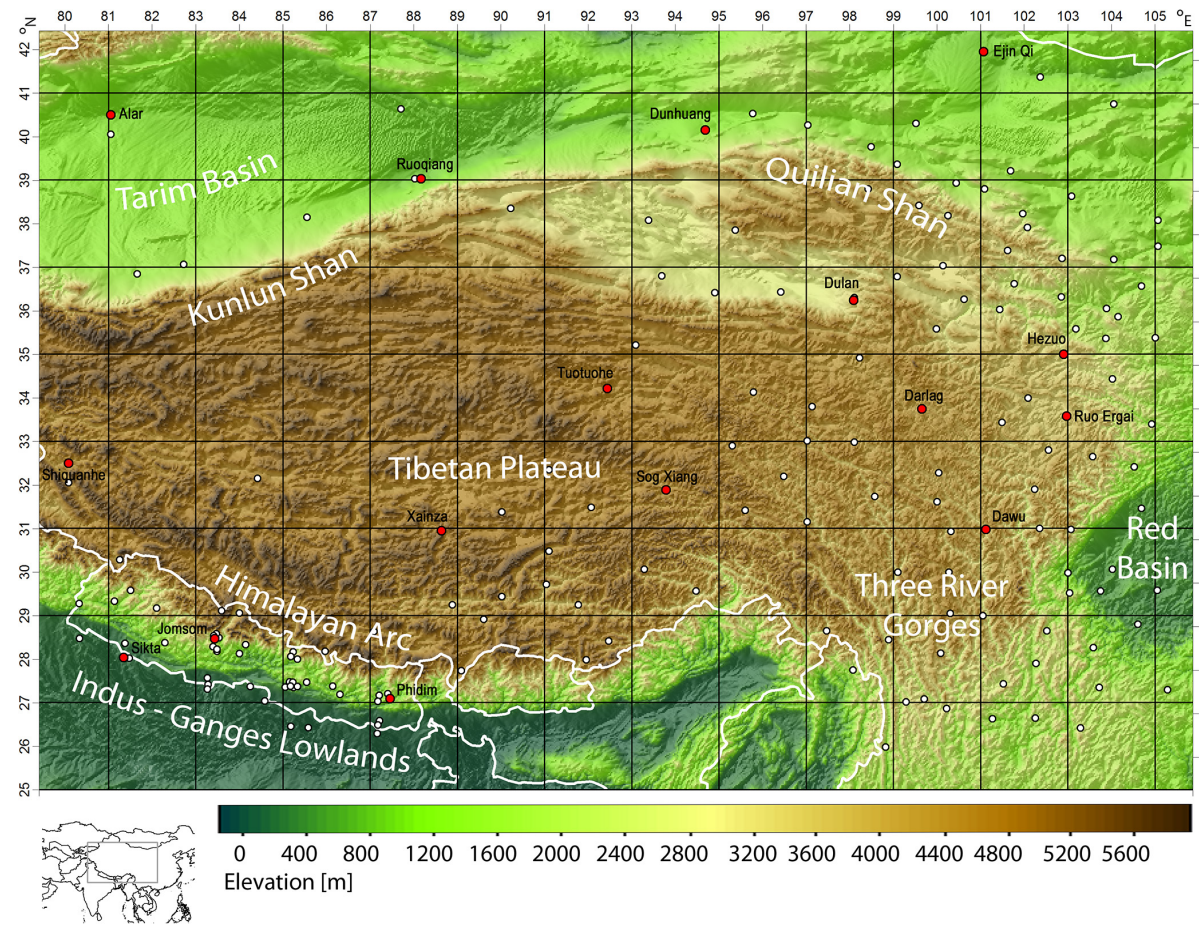

Figure 1. The target area and its main geomorphological features. The white dots indicate the locations of meteorological stations used for the implementation of the statistical downscaling model. The locations marked in red were used for the model evaluation.

a permanent component of the large-scale summer monsoon system, which controls trajectories of monsoonal disturbances south of the Himalayas tracking from east to west as well as the alternating formation of convection cells and frontal rains in southeastern Tibet (Böhner, 2006; Domrös, 1988; Flohn, 1987). Due to lower radiation influx and thermal capacity, strong high-pressure cells form over the adjacent Indian and Pacific Ocean. Thus the shallow trough over Tibet leads to converging moist air masses over the Asian continent (Maussion et al., 2014). The Himalayan Arc acts as a barrier to the near-surface monsoonal currents, which results in an orographic uplift of moist air masses and strong convection over India and the southern slopes of the Himalayas and eventually in the formation of the monsoon trough over the Indian Lowlands (Böhner, 2006). The main moisture fluxes for the South Asian summer monsoon originate over the Bay of Bengal and lead to intensive and perpetual precipitation over the eastern Indus-Ganges Lowlands and the adjacent mountain ranges. The moist air masses penetrate the meridional Three River Gorges and lead to enhanced precipitation rates in southeastern Tibet. A minor monsoonal current advects moist air masses from the Arabian Sea into western India and the western Himalayas (Sigdel and Ikeda, 2012). Since the western monsoonal current is weaker, a clear east-west gradient of summer precipitation rates over the Indus-Ganges Lowlands and the Himalayan Arc can be observed (Böhner, 2006; Wulf et al., 2010). The central and western areas of the central-western
Tibetan Plateau are less directly influenced by monsoonal air masses. Precipitation events are mainly associated with diurnal local-scale convection due to high rates of solar irradiation (Maussion et al., 2014).

The easternmost parts of the investigation area are mainly influenced by the East Asian summer monsoon. The advection of dry continental air from northern directions and the flux of moist tropical air originating from the western Pacific lead to intensive front formation in the middle troposphere of the polar mixing zone. The resulting quasi-stationary front and its associated rain regimes cover large domains over East Asia (Böhner, 2006).

The northern part of the target area remains north of the Intertropical Convergence Zone (ITCZ) during summer and hence is mainly influenced by extratropical westerlies. However due to the shadowing effect of the Pamir, Karakoram and Tian Shan mountain ranges (outside of the target area), the Tarim Basin remains dry, with summer precipitation rates below $25 \mathrm{~mm}$ (Xu et al., 2004). Only the elevated and western exposed regions of the Kunlun and Quilian Shan receive summer precipitation due to western cyclonic activity (Böhner, 2006). During the post-monsoon season, the pressure cells over Asia and the adjacent oceans dissolve and the ITCZ shifts southward. The area influenced by western circulation patterns spreads south and reaches the Himalayan Arc in winter season. The Tibetan Plateau and the continental regions of central Asia now act as a cold source, resulting in the formation of the Asiatic High over Mongolia and 
northern China. The associated strong pressure gradients between the high-pressure cell over Asia and its counterparts, the Aleutian Low over the Pacific Ocean and the ITCZ over the Indian Ocean, lead to a divergent near-surface flow over central and High Asia. Thus the target area is under the influence of dry continental air masses. The $200 \mathrm{hPa}$ jetstream at the planetary frontal zone reaches its southernmost position in January at $35^{\circ} \mathrm{N}$. Due to the blocking effect of the Tibetan Plateau, the jetstream is divided into two branches. While the northern current is situated near the Altai Mountains (north of the target area), the southern branch follows the slopes of the Himalayas. The western Himalayas, particularly west-facing slopes, receive a considerable amount of winter precipitation associated with the uplift of the westerly flow and western disturbances brought by the $200 \mathrm{hPa}$ jetstream. Thus winter precipitation events in the target area are mainly triggered by circulation modes of the temperate latitudes (Böhner, 2006; Filippi et al., 2014; Maussion et al., 2014; Wulf et al., 2010). The eastern parts of the study area receive less precipitation due to the shadowing effect of the Tibetan Plateau and the mountain ranges of High Asia. The Indian plains are under the influence of the subtropical subsiding motion of the Hadley cell and are characterized by stable atmospheric conditions (Böhner, 2006). In spring the pressure gradients over Asia decrease due to increasing solar irradiation. The northern branch of the $200 \mathrm{hPa}$ jetstream strengthens, and the major trajectories of the western disturbances shift northward. The Indus-Ganges Lowlands and especially the southern Himalayan slopes receive high solar radiation, which results in occasional convective precipitation events (Romatschke et al., 2010).

Investigation of the interannual variability of precipitation rates over central and High Asia often focuses on the summer monsoon season. Most studies (Li and Yanai, 1996; Peings and Douville, 2010; Prodhomme et al., 2015) reveal that the intensity of the monsoon highly depends on the magnitude of pressure gradients. Since the formation and intensity of the low-pressure cell over Asia is mainly triggered by the radiative heating of the Tibetan Plateau, an enhanced snow cover during winter and spring increases the surface albedo and results in a delayed and reduced formation of the thermal low and subsequently in decreasing summer precipitation amounts. Moreover, many studies highlight the importance of the Southern Oscillation for the intensity of monsoonal precipitation (Sankar et al., 2011; Shrestha, 2000), although some studies illustrate that the correlation of the Southern Oscillation index (SOI) and the Indian and the East Asian summer monsoon precipitation weakened during recent decades (Kumar et al., 1999; Wang and He, 2012). Studies by Pokhrel et al. (2012) and Sigdel and Ikeda (2012) indicate that El Niño events are accompanied by reduced moisture fluxes into South Asia. Preethi et al. (2011) point out that the severe 2009 drought over India was at least partially triggered by a weak El Niño event. The variability of winter precipitation is mainly related to the magnitude of the pressure gradients and the position of the planetary frontal zone and the accompanying westerly jetstream (Dimri et al., 2013).

On the local scale, the precipitation distribution over the target area is extremely modified due to the various interactions of moist air masses with complex topography and the accompanying local-scale atmospheric processes (Chen et al., 2014; Guan et al., 2009; Suprit and Shankar, 2008). Many studies show that the elevation plays a crucial role in the distribution of precipitation, although the vertical precipitation gradient in high-mountain regions varies considerably in different target areas. While some studies indicate increasing precipitation amounts up to highest elevations, others assume an elevational threshold, followed by stationary or even decreasing values (Barry, 2012). The near-surface monsoonal currents during summer generate high precipitation rates at the southern Himalayan slopes up to elevations of $4000 \mathrm{~m}$, followed by a sharp decrease above at the southern Himalayan slopes (Barros et al., 2000; Shrestha et al., 2012). The cyclogenetic winter precipitation reaches higher elevations, due to orographic uplift of the westerly flow. In general the windward slopes receive enhanced precipitation. The orographic precipitation reaches annual amounts of up to $10000 \mathrm{~mm} \mathrm{a}^{-1}$ in the Kashi Hills in northern India. In contrast, the leeward areas of the Trans-Himalaya are characterized by arid conditions even during summer (Böhner, 2006). Based on the remote-sensing-derived Tropical Rainfall Measuring Mission (TRMM), Bookhagen and Burbank (2006) show that the topography of the southern Himalayan slopes is the main trigger for the local-scale precipitation distribution. While the central Himalayas are characterized by a so-called one-step topography, which results in a distinct band of maximal precipitation rates south of the main mountain ranges, the eastern and western parts show a second band of high precipitation at lower elevations due to the orographic barrier of the lesser Himalayas (Böhner, 2006; Maussion et al., 2014). The precipitation rates in high-mountain regions are further modified by autochthonous local-scale circulations, such as the diurnal valley-mountain breeze. The enhanced irradiation at the mountain slopes leads to slope-upward winds and subsiding air motions over the valley bottoms. This results in convection and occasional precipitation events over the slopes, while the valleys remain dry (Böhner and Antonić, 2009).

\section{Data and methods}

Gridded climate reanalysis products, such as ERA-Interim (developed at the European Centre for Medium-Range Weather Forecast, ECMWF), simulate 6-hourly large-scale atmospheric fields for 60 pressure levels between 1000 and $1 \mathrm{hPa}$ over Asia with a horizontal resolution of $0.7^{\circ}$ lat/long (T255) (Berrisford et al., 2009; Dee et al., 2011). Since the ERA-Interim reanalysis combines modeling results with ground and radiosonde observations and remote sensing data 
using a data assimilation system, the free-atmospheric fields can be considered as the best guess of the current largescale atmospheric situation for every time step. Many studies reveal that ERA-Interim adequately captures the variability of relevant free-air meteorological parameters, even over complex mountain regions (Bao and Zhang, 2012; Gao et al., 2012). Recent evaluations of different reanalysis products show that ERA-Interim has the best accordance with in situ observations derived from near-surface meteorological records (Bao and Zhang, 2012) and radiosonde observations over the Tibetan Plateau (Wang and Zeng, 2012) and the central Himalayan Arc (Jin-Huan et al., 2013). These results were particularly evident for temperature, wind direction and velocity, and hydroclimatological parameters. Due to the assimilation of in situ radiosonde and near-surface observations, we assume that the precipitation relevant moisture fluxes are well represented by ERA-Interim. Sigdel and Ikeda (2012) show that the interannual variability of moisture transports into the target area (e.g., because of variations in the Southern Oscillation) can be captured by reanalysis products. However, their coarse resolution is insufficient to represent the spatial variability of sub-grid atmospheric processes in the highly structured study area. For the analysis of local-scale precipitation rates we utilized daily observations from 173 meteorological stations which were available from 1989 onwards. A total of 157 records were used for the model calibration based on the period from 1989 to 2000. A further 16 station records for the period from 2000 to 2011 were used for the evaluation of the modeling approach (Fig. 1). Thus the validation data set is spatially and temporally independent of the model implementation. The station records for the evaluation procedure were subjectively chosen with the objective of representing all major geographic subregions of the target area and their specific climate characteristics. The data sets in general showed a sound data quality; missing values were deleted. The observations for China and Tibet were provided by the China Meteorological Administration, the records for Nepal were supplied by the Department of Hydrology and Meteorology, Kathmandu, Nepal. All station records were quality-proofed using the Neumann ratio for annual precipitation sums. Further, the cumulative residuals were tested as suggested by Buishand (1982). Records showing significant inhomogeneities on the $99 \%$ level were rejected. The precipitation time series were aggregated to monthly sums. For a rough assessment of the temporal precipitation distribution we used the maximum daily amount as well as the number of rainy days as additional predictand variables.

\subsection{Atmospheric and topographic predictors}

For the characterization of the large-scale atmospheric pressure distribution over Asia, a principal component analysis (PCA) of the ERA-Interim $500 \mathrm{hPa}$ geopotential height (GPH) fields was conducted for the macrogeographical region between $50^{\circ} \mathrm{N}$ and $10^{\circ} \mathrm{S}$ and 30 and $140^{\circ} \mathrm{E}$. This al- lows for identification of the major spatial modes and the temporal variability of the atmospheric circulation over the target area. The PCA decomposes the time series of gridded GPH fields to a small number of orthogonal atmospheric patterns (referred to as eigenvectors or empirical orthogonal functions, EOFs) and accompanying uncorrelated time indices (scores) (Hannachi et al., 2006). The atmospheric pattern for every time step can then be described as a linear combination of the EOFs and scores. Typically the major part of the large-scale atmospheric variability can be explained by only a small number of EOF fields (Hannachi et al., 2007). This leads to a reduction in the dimensionality of complex systems and removes internal redundancies. The PCA was conducted based on anomalies of the $500 \mathrm{hPa}$ ERA-Interim monthly mean GPH compared with the longtime mean for the period from 1989 to 2010. For the computation we utilized the package "prcomp" within the free and open-source software R. We considered those fields which contribute to more the $1 \%$ of the total variance of the spatiotemporal GPH distribution. Since the position of the major pressure cells over Asia and the adjacent oceans determines the prevailing wind directions and the moisture transport into the target area, the EOF fields are useful to interpret the circulation variability and the accompanied precipitation-forming atmospheric processes. The scores indicate the relevance of the EOF patterns for the pressure distribution of each month and were used as large-scale predictors for the presented downscaling approach.

Figure 2 shows the major six EOF fields and the appendant time series of scores, as well as their portion of variance explained. The first EOF indicates the seasonal shift of the ITCZ and the associated north-south pressure gradient between the Asian continent and the Indian Ocean. During summer the continent is characterized by a thermal lowpressure cell, which results in an uplift of the $500 \mathrm{hPa}$ GPH. At the same time, the Indian Ocean is under the influence of the southern branch of the Hadley cell, which results in higher sea level pressure and a decrease in the $500 \mathrm{hPa}$ level GPH. In winter season the large-scale atmospheric conditions turn due to the southward shift of the ITCZ. The scores of the first EOF show a clear annual cycle: the summer circulation pattern is characterized by positive, and the winter pattern by negative scores. The second EOF field addresses a pressure gradient from east to west over the Asian continent. Again the scores suggest an annual cycle of the second EOF, with mainly positive values during summer and negative values during winter. This is attributed to the formation of a thermal low-pressure cell over central Asia during summer. However the time series of scores show an interannual variability which is significantly correlated with the index of the Southern Oscillation, defined as $\mathrm{SOI}=\frac{\Delta P-\Delta P_{\text {avg }}}{s_{\Delta P}}$, where $\Delta P$ indicates the sea level pressure difference between Tahiti and Darwin. $\Delta P_{\text {avg }}$ is the mean pressure difference and $s_{\Delta P}$ is the accompanying standard deviation $(r=-0.51, p=0.99)$. 


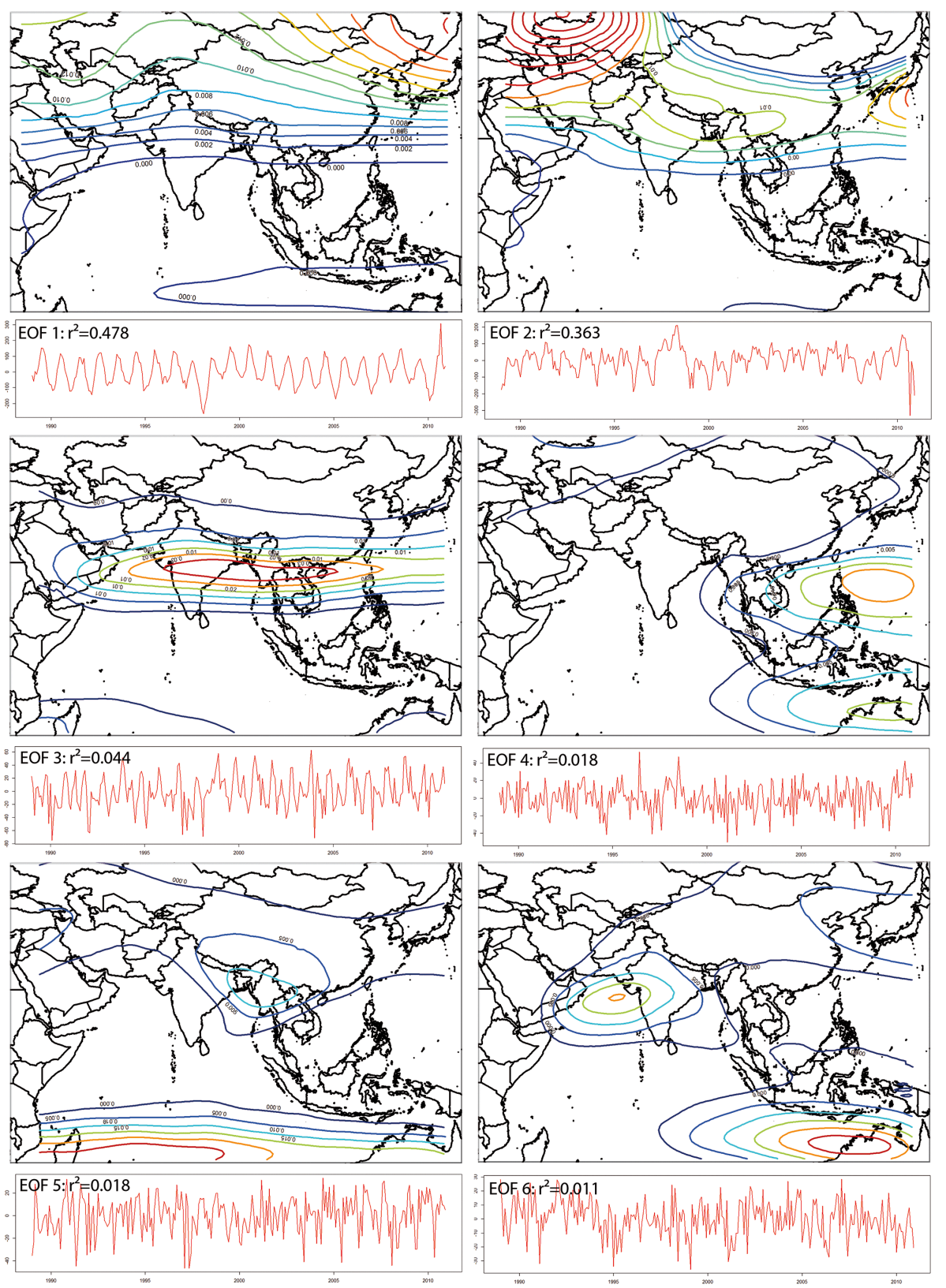

Figure 2. Spatial modes and time series of scores for the first six EOFs of the $500 \mathrm{hPa}$ GPH anomaly over the macrogeographical region. Blue (red) lines indicate low (high) values of the particular EOF.

The extreme 1997/1998 El Niño event in particular is clearly evident in the time series of EOF scores (Kirono et al., 1999; Slingo and Annamalai, 2000; Wang et al., 2002). The first two EOFs already contribute to $84.1 \%$ of the temporal largescale variability of the GPH over the selected region. The third EOF field (which explains an additional $4.4 \%$ of the GPH variability) indicates the uplift and lowering of the $500 \mathrm{hPa}$ level over northern India and Southeast Asia.

This band coincidences with the position of the Tropical Easterly Jet during summer and the trajectories of tropical disturbances (Parth Sarthi et al., 2014).
The fourth EOF pattern addresses an east-west-oriented pressure gradient over the Indian Ocean. Pattern five alludes to variations in the $500 \mathrm{hPa}$ level GPH over the southern Indian Ocean; pattern six indicates variations in the simultaneous formation of pressure cells over the Arabian Sea and the Australian continent.

For the characterization of precipitation relevant synoptic situations we further processed the ERA-Interim monthly means of relative humidity at the 500 and $200 \mathrm{hPa}$ level. These fields were resampled to a grid size $1 \mathrm{~km}^{2}$ using a thin-plate spline and were extracted for every single meteoro- 
logical station. Since the downscaling approach utilizes only free-atmospheric fields as large-scale predictor variables, the interpolation to high spatial resolution appears reasonable. Many studies (Corbosiero and Molinari, 2002; Frank and Ritchie, 2001; Wingo and Cecil, 2009) mention the vertical wind shear between the 500 and $200 \mathrm{hPa}$ level as an important factor for the spatial and temporal precipitation distribution, particularly with regard to tropical disturbances. Thus the wind shear was derived from the ERA-Interim reanalysis and likewise resampled to the required resolution of $1 \mathrm{~km}^{2}$.

For the analysis of interactions between the large-scale synoptic situation and the varying topographic settings of the target area, specific terrain parameters were integrated into the downscaling approach. These were derived from the SRTM digital elevation model (Farr et al., 2007) and aggregated to a $1 \mathrm{~km}^{2}$ resolution. Primarily the raw surface elevation $(Z)$ controls the precipitation distribution in complex terrain (Daly et al., 1994). The vertical precipitation gradient in mountainous regions is often exaggerated due to the diurnal mountain-valley circulation and the associated convection at the mountain slopes. To account for the spatial variations in terrain-induced convection, we utilized the relative elevation above the channel network $\left(Z_{\text {rel }}\right)$ as an additional predictor variable. Therefore the channel lines were identified and interpolated for the target domain. The elevation above channel line is subsequently calculated as a difference of the surface elevation and the interpolated channel altitudes. The methods for the derivation of the relative elevation above the channel network are available as a complete tool in the free and open-source geographical information system (GIS) SAGA (Böhner and Antonić, 2009).

Orographic precipitation, resulting from the uplift of moisture-bearing air masses at windward slopes of topographic barriers and the related leeward rain shadow, is probably the most prominent feature of the spatial precipitation distribution in the target area. Based on the assumption that the windward impact on the precipitation intensity depends on the prevailing large-scale wind direction and on the elevation of the orographic barrier, a wind index (as suggested by Böhner and Antonić, 2009) was used for the presented study. For the Tibetan Plateau, with its mean elevation between 4000 and $5000 \mathrm{~m}$, the $500 \mathrm{hPa}$ wind field can be considered as near surface; in addition, the wind and leeward effects of the major mountain ranges influence the $500 \mathrm{hPa}$ level wind field. It should be mentioned that the $500 \mathrm{hPa}$ level does not represent near-surface conditions for the peripheral lowlands; however, we assume that the annual cycle of prevailing wind directions is depicted by the $500 \mathrm{hPa}$ level. Thus we resampled the monthly mean ERA-Interim $500 \mathrm{hPa}$ wind fields to the target resolution of $1 \mathrm{~km}^{2}$ and subsequently derived the windward and leeward positions. For every grid cell, the wind trajectories were followed and the weighted vertical angles of the flow currents analyzed using the following equations.
The windward index $H_{\mathrm{W}}$ and the leeward index $H_{\mathrm{L}}$ were calculated to

$$
\begin{aligned}
& H_{\mathrm{W}}=\frac{\sum_{i=1}^{n} \frac{1}{d_{\mathrm{WH} i}} \cdot \tan ^{-1}\left(\frac{d_{\mathrm{WZi}}}{d_{\mathrm{WH} i}}\right)}{\sum_{i=1}^{n} \frac{1}{d_{\mathrm{LH} i}}+\frac{\sum_{i=1}^{n} \frac{1}{d_{\mathrm{LH} i}} \cdot \tan ^{-1}\left(\frac{d_{\mathrm{LZ} i}}{d_{\mathrm{LH} i}}\right)}{\sum_{i=1}^{n} \frac{1}{d_{\mathrm{LH} i}}},} \\
& H_{\mathrm{L}}=\frac{\sum_{i=1}^{n} \frac{1}{\ln \left(d_{\mathrm{WH} i}\right)} \cdot \tan ^{-1}\left(\frac{d_{\mathrm{LZi}}}{d_{\mathrm{WH} i}}\right)}{\sum_{i=1}^{n} \frac{1}{\ln \left(d_{\mathrm{LH} i}\right)}},
\end{aligned}
$$

where $d_{\mathrm{WH} i}$ and $d_{\mathrm{LH} i}$ refer to the horizontal distances in windward and leeward direction and $d_{\mathrm{WZ} i}$ and $d_{\mathrm{LZ} i}$ are the corresponding vertical distances compared with the considered raster cell. The second summand in Eq. (1) accounts for the leeward impact of previously traversed mountain chains. The logarithmized horizontal distances in Eq. (2) lead to a longer-distance impact of leeward rain shadow. The final wind-effect parameter, which is supposed to be related to the interaction of the large-scale wind field and the local-scale precipitation characteristics, is calculated as $H=H_{\mathrm{L}} \cdot H_{\mathrm{W}}$ and takes values between 0.7 for leeward and 1.3 for windward positions (Böhner and Antonić, 2009). The cellwise calculation of the wind effect is likewise fully implemented in SAGA GIS.

Figure 3 shows the spatial distribution of the wind effect as well as the mean $500 \mathrm{hPa}$ wind field for January and July 2010. The upper picture shows the complete target area, while the lower one is an enlargement of the central Himalayan Arc. The winter situation is characterized by a homogenous westerly flow which results in high values of the wind-effect parameter at the western slopes, particularly at the margins of the Kunlun Shan, the Quilian Shan and the Himalayas. During summer the thermal low over the Tibetan Plateau is fully established, resulting in a converging flow pattern at the $500 \mathrm{hPa}$ level. The northwesterly monsoonal currents over southern Asia lead to maximal values of the wind-effect parameter at the southern Himalayan slopes. Especially the first mountain ranges north of the Nepalese border and the major Himalayan peaks are characterized by strong windward positions. In contrast, the eastwest-oriented valleys of central Nepal are located in the rain shadow of the lower Himalayas. The strong leeward position of the Trans-Himalayan valleys north of the major peaks is particularly well captured by the spatial distribution of the wind-effect parameter.

To account for varying interactions of large-scale atmospheric processes and topographic characteristics in the versatile subregions of the target area, the geographical coordinates (lat/long) were considered as further explanatory variables for the presented downscaling approach. 
Finally, all predictor and predictand variables were normalized by subtracting the mean values and dividing by the corresponding standard deviation.

\subsection{Implementation and evaluation of an ANN model}

Traditional statistical methods, most notably linear models, have been frequently used for the quantification of statistical relationships and the implementation of transfer functions (e.g., Böhner, 2006), although the actual predictorpredictand relations are often highly nonlinear (Gerlitz, 2014; Sauter and Venema, 2011). Furthermore, the data sets used often violate the statistical conditions, e.g., in the case of intercorrelated predictor variables or non-normal-distributed and non-homogenous residuals (Schönwiese et al., 2010; Schoof and Pryor, 2001). During the last decade, complex machine learning algorithms such as artificial neural networks have become more prominent in the field of geoscientific research and have been utilized, for example, for hydrological simulations (Dawson and Wilby, 2001; Jain and Kumar, 2007), snow cover prediction (Sauter and Venema, 2011) and habitat modeling (Özesmi and Özesmi, 1999), as well as for statistical downscaling and climate modeling applications. For the analysis and prediction of the variability and change of monsoonal precipitation rates over India, various recent studies have applied ANNs, attaining reliable results (Chattopadhyay, 2007; Shukla et al., 2011; Singh and Borah, 2013). In the field of precipitation downscaling ANNs were utilized (amongst others) by Coulibaly et al. (2005), Dibike and Coulibaly (2006), Mekanik et al. (2013) and Tomassetti et al. (2009). All studies highlight the complexity and nonlinearity of the climate system with particular regard to precipitation-forming processes. A comprehensive review of studies on rainfall prediction based on neural network applications is given by Ranjan Nayak et al. (2013). Schoof and Pryor (2001) compared the predictive performances of neural-network-based downscaling approaches with linear-regression-based methods and concluded that ANNs are superior at capturing complex interactions between the large-scale synoptic patterns and localscale observations, although they point out that the results of precipitation downscaling approaches do not achieve the quality of comparable temperature estimations.

Compared to linear models, ANNs stand out due to their flexibility and their capability to approximate any nonlinear continuous function. The data-driven non-parametric approach can identify input-output relationships without any prior assumptions and can handle intercorrelated predictor variables, which is advantageous if complex systems are to be analyzed and the specific type of internal relationships and interactions is unknown (Günther and Fritsch, 2010; Sauter et al., 2009). Inspired by our conception of the human brain, ANNs are composed of numerous simple parallel operating processing units (referred to as neurons) and associated weights (synapses). The neurons are generally arranged in layers, starting with the input layer, which contains one neuron for each independent variable $\xi$, one or more hidden layers with an arbitrary number of neurons for the processing of the data, and one output layer, which releases the final modeling results. Since an ANN with one hidden layer can already approximate any continuous differentiable function (Schoof and Pryor, 2001), multilayer ANNs are seldom used for regression applications.

Figure 4 shows exemplarily a neural network architecture with three input variables, one hidden layer with two processing units, and one output variable. The input passes the vector of time series of the independent variables to the hidden neurons. These receive a signal which is determined by the socalled integration function net ${ }_{j}$, defined as a weighted linear combination of the predictand vectors. To account for nonlinearities of the input-output relationships, the neurons process the signal by means of the activation function $\varphi$, which is usually defined as a sigmoid logistic function, mapping the values of the integration function to a domain $\in[0 ; 1]$. The value 1 refers to a strong effect of the particular linear combination of the input vectors for the output result, while 0 indicates a negligible influence. In the final output layer the activation function is linear. For the calculation of the output $o_{j}$ of any neuron $j$, the activation function is applied to the net result of the weighted linear combination net ${ }_{j}$.

$o_{j}=\varphi\left(\right.$ net $\left._{j}\right)$ with net $j=\sum_{i=1}^{n} w_{i} \cdot x_{i}$ and $\varphi=\frac{1}{1+e^{\text {net }_{j}}}$

Most ANNs are constructed using a three-layer architecture with only one hidden layer, where the processing of the data is conducted. For the presented study we utilized a feedforward ANN, i.e., the information flow is unidirectional. Each neuron receives signals from all nodes of the previous layer and passes the modified signal to the nodes of the subsequent one. The knowledge of an ANN is comprehended in the weights of the integration function. These are initially assigned as random values of the normal distribution. The initial network processes the input vectors based on the integration and activation functions of the internal neurons and passes an output signal to the final layer. Since the weights are randomly chosen, the output of the ANN model, compared with observed values, is primarily insufficient. Based on a learning sample, the weights are subsequently iteratively adjusted with the aim of minimizing the error function, defined as the root-mean-square error of the desired predictand values and the outcome of the ANN model. For the adjustment of weights, several supervised learning algorithms were developed, although most ANN applications are based on the so-called backpropagation approach (HechtNielsen, 1989). This algorithm calculates the gradient of the error function with regard to modified weights backward in the network and shifts the weights into the opposite direction of the partial derivates based on a default learning rate. The recursive application of the backpropagation procedure en- 


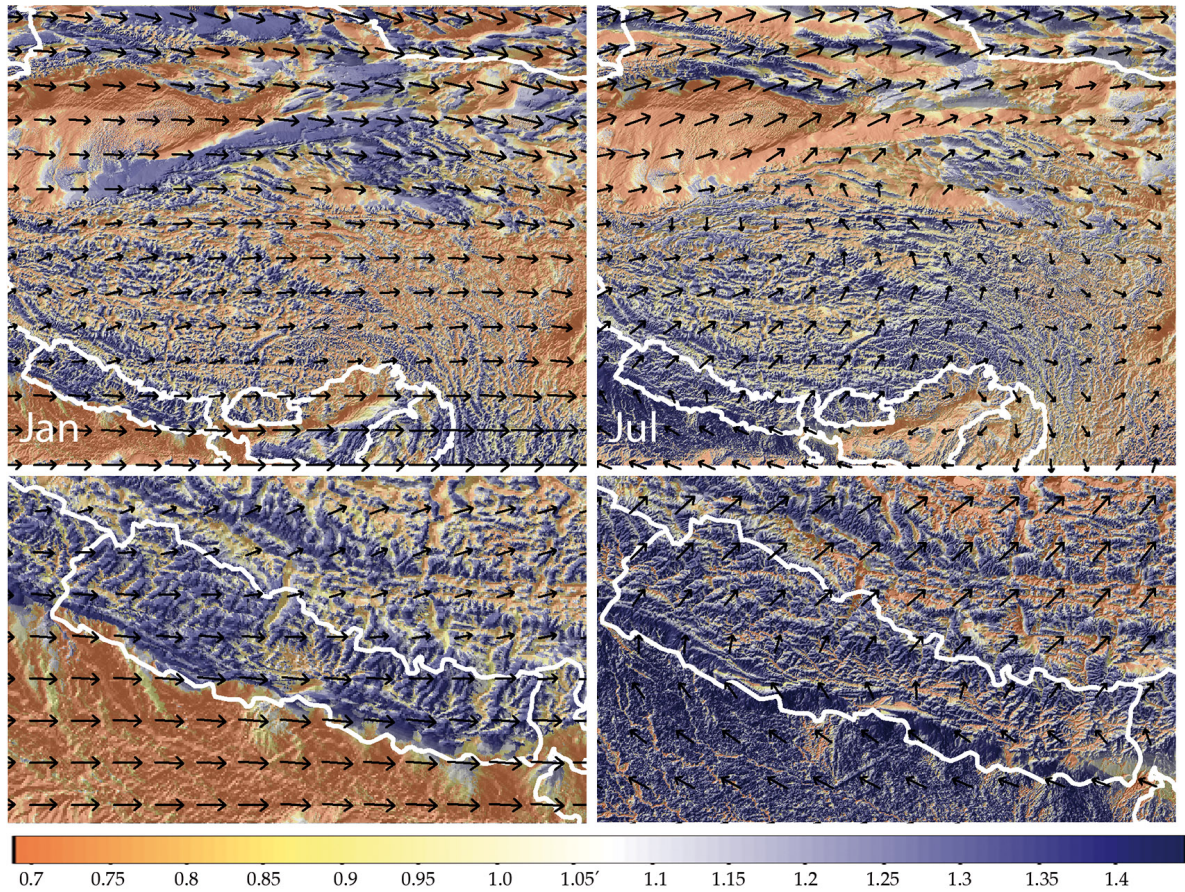

Figure 3. The spatial distribution of the wind-effect parameter for January and July 2010. The arrows represent the 500 hPa ERA-Interim wind field.

sures the identification of a local minimum of the error function and the corresponding weights. To discover the best neural network for the regression of the local-scale precipitation rates as a function of the abovementioned predictor variables, we utilized the resilient backpropagation approach, which is fully implemented in the R package "neuralnet" (Günther and Fritsch, 2010). This algorithm increases the learning rate if the direction of the error gradient keeps its sign. If the sign turns, the learning rate is decreased automatically. This leads to an accelerated conversion of the recursive adjustment of weights and avoids a minimum being missed due to a too large learning rate.

The most obvious degree of freedom of any ANN approach is its architecture, particularly the number of neurons within the hidden layer. Although rules of thumb for the best number of neurons have been suggested (Basheer and Hajmeer, 2000), a general rule, defining the best ANN architecture, has yet to be determined. While an ANN model with too many neurons in the hidden layer tends to overfit, which results in a poor predictive performance, an insufficient number of neurons leads to an overgeneralization and hence nondetection of distinct nonlinear relationships within the learning sample. The best ANN architecture highly depends on the number of predictor and predictand variables, the number of cases, and the type and complexity of the statistical relationship (Sauter et al., 2009). Thus, for the identification of an optimum ANN for the downscaling approach, we tested several ANN architectures with regard to their predictive power. Starting with only one neuron in the hidden layer, the com-

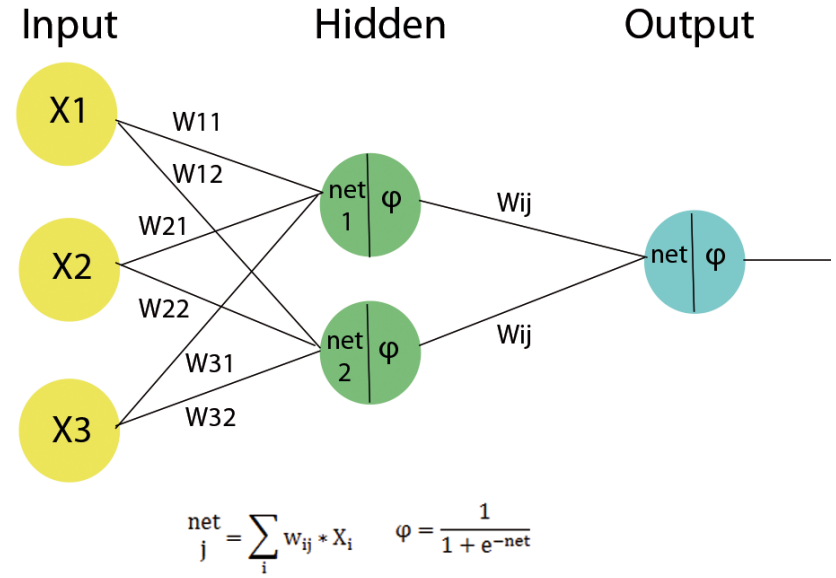

Figure 4. Schematic structure of a feed-forward artificial neural network model and the equations for the integration function netj and the activation function $\varphi$.

plexity of the network was gradually increased. Due to exponentially increasing computing demands in the learning phase, the maximum number of neurons was set to 10 . For each of the neurons, an ANN was implemented based on the learning sample containing monthly time series of 157 meteorological stations for the period from 1989 to 2000. The vectors of predictor variables were used as input nodes. The observed monthly precipitation sum, the maximum of daily precipitation and the number of rainy days were chosen as 

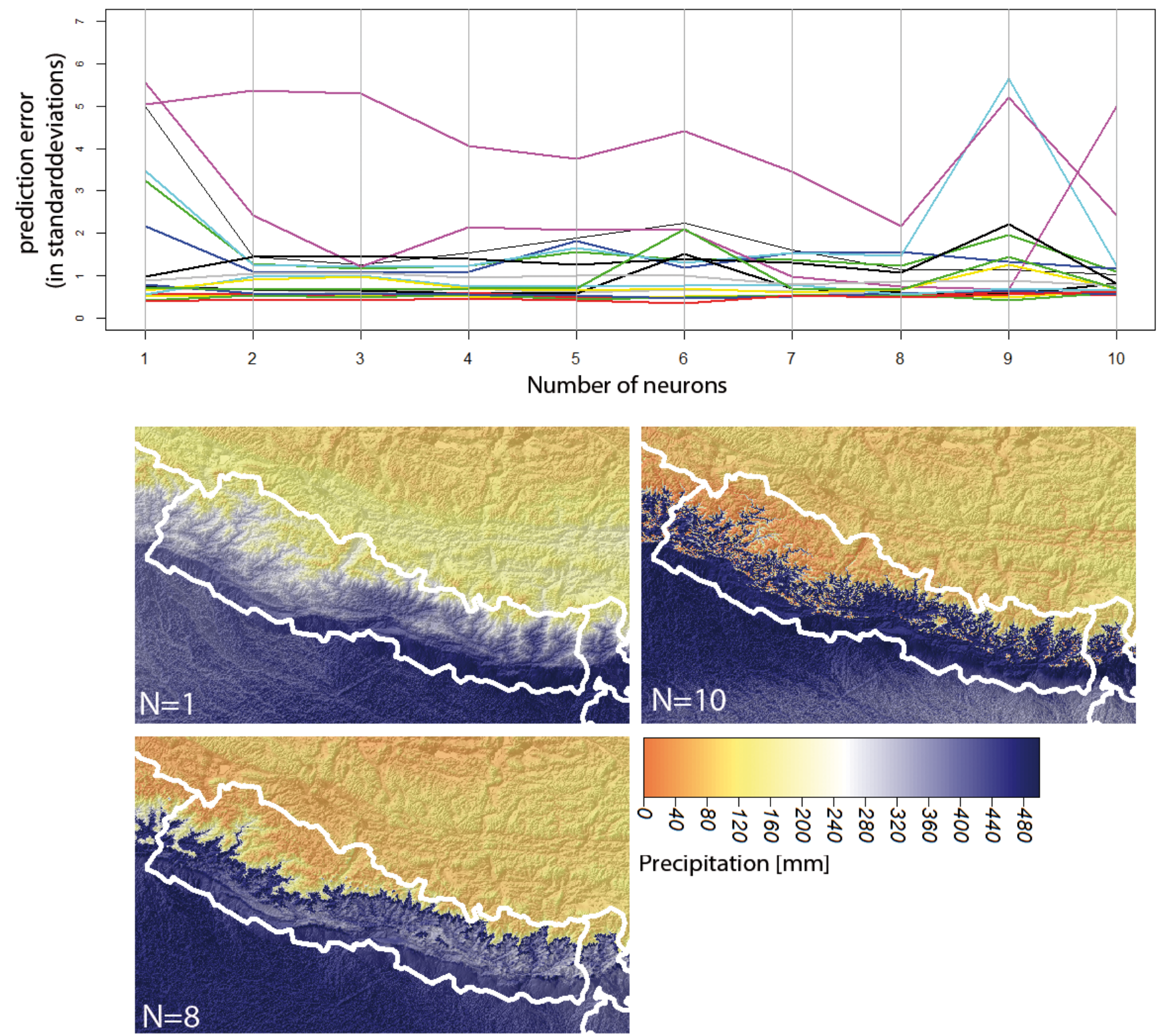

Precipitation [mm]

Figure 5. Normalized prediction error of various ANN architectures for 18 independent observational records (top panel) and the modeled distribution of precipitation sums for July 2010 over Nepal based on ANN architectures with $N=1, N=8$ and $N=10$ neurons.

output variables. Every ANN realization was used to predict the output variables for an independent evaluation data set. Due to the disproportionally high computing demands of cross-validation techniques, we exemplarily evaluated the ANN performance based on time series from 16 stations for the period 2001 to 2011 (see red dots in Fig. 1). These subjectively chosen stations cover different climatic subregions and thus enable the evaluation of the model under varying pluviometric regimes. The fact that the evaluation data set is temporally and spatially independent facilitates the prevention of overfitting of both large-scale atmospheric and local-scale topographic predictor variables. For the evalua- tion of the model, the mean squared residuals of each station were calculated and normalized using the mean and the standard deviation of the particular record of observations. This enables the comparison of the model quality for stations with varying precipitation amounts. Figure 5 shows the mean squared error (in standard deviations) of the monthly precipitation sums for each of the evaluation records. The ANN realizations with only a few neurons in the hidden layer show large residuals for some stations. This is due to an extreme overestimation of precipitation rates for the dry regions in the north of the study area (not shown). With increasing complexity the model better captures the diverse climates 
of the target area and improves the prediction performance for the evaluation data records. The ANN with eight hidden neurons was found to have the lowest prediction error of the monthly precipitation sums (with values below 0.5 standard deviations for most of the meteorological stations) and hence was used for the cellwise estimation of precipitation rates in the target area. The analysis of the prediction power for the maximum daily precipitation and the number of rainy days revealed similar results (not shown). For ANN architectures with more than eight hidden neurons, the prediction performance of the model decreased considerably. The maps in Fig. 5 exemplarily show the predicted fields of precipitation sums for the central Himalayan region for July 2010 based on varying ANN architectures with $N=1, N=8$ and $N=10$ hidden neurons. The simple ANN with only one neuron in the hidden layer does not capture the topographically determined precipitation distribution and mainly depicts an elevational gradient of precipitation sums with high values in the Indus-Ganges Lowlands and lower values in the high mountains and on the elevated Tibetan Plateau. In contrast the ANN with 10 hidden neurons clearly overfits the inputoutput relationships, resulting in a rather unrealistic scattered precipitation field, particularly over the highly complex terrain of the southern Himalayan slopes. The precipitation distribution predicted by the "best" ANN architecture with eight hidden neurons depicts two major precipitation bands, one at the first topographic barrier of the outer Himalayas and one at the southern margin of the highest mountain peaks, as well as a sharp decrease in precipitation amounts above $4000 \mathrm{~m}$.

These results highly agree with previous studies on the topographically induced distribution of precipitation rates in the target area (Bookhagen and Burbank, 2006; Maussion et al., 2014; Shrestha et al., 2012) and support the reliability of the statistical model. Figure 6 compares the modeled and observed time series of monthly precipitation sums for the 16 independent stations. The spatial distribution of precipitation (with annual precipitation sums ranging from below $50 \mathrm{~mm}$ over the Tarim Basin to more than $2000 \mathrm{~mm}$ over the monsoon-influenced Himalayan slopes) is well simulated by the ANN model. However for the stations in the central Asian deserts and at the southern Himalayan slopes, particularly for Jomsom, which is located in the bottom of the deeply carved Kali Gandaki Valley in central Nepal, the model clearly overestimates the precipitation amounts.

For all other records the annual precipitation amounts are properly simulated with deviations of annual precipitation sums below $20 \%$. The seasonal variability in monthly precipitation sums, with highest values during summer, is well captured for the complete target area. The locations of Darlag, Darwu and Tuotuohe (all situated at elevated sites on the Tibetan Plateau) and Sikta (at the southern Himalayan slopes) receive a considerable amount of winter precipitation, which is (although distinctly overestimated for the station Darlag) in general well captured by the ANN model. The interannual variability of precipitation rates is particu- larly obvious for the monsoon season. The well-documented 2009 drought over India and the Himalayas (Preethi et al., 2011) is clearly evident in the observed and modeled time series of precipitation sums for Jomsom, Phidim and Sikta. Likewise, for the arid landscapes in the northern part of the model domain, the major variations in annual precipitation amounts are well captured. The obvious feature of low precipitation rates during 2009 and considerably higher values in the following year are particularly evident in observations and modeling results. The interannual variability of moisture fluxes into the western Tibetan Plateau and the accompanying variability of precipitation rates are likewise well simulated by the modeling results. The extremely dry year 2009 at the station Shiquanhe is particularly evident in both data sets. The explained variance of the ANN model ranges from approximately 0.5 for the convection-dominated stations in the arid landscapes in the north of the study region to the considerable value of 0.75 in the monsoon-influenced areas south and east of the Tibetan Plateau.

Although the validation was conducted exemplarily and more sophisticated and computationally demanding techniques (e.g., k-fold cross-validation or an evaluation based on additional data sets, which were used for neither the model calibration nor the choice of an adequate network architecture) would certainly better assess the overall performance of the model, the results indicate that both the spatial and temporal variability are well captured by the statistical approach. The fact that the local-scale topographically induced precipitation distribution coincides with remotesensing-derived precipitation products (Bookhagen and Burbank, 2006; Shrestha et al., 2012) in particular supports the feasibility of the suggested downscaling approach.

Based on the gridded modeling results, a detailed analysis of the temporal and spatial precipitation distribution in the target area and its essential influencing factors is given below.

\section{Results}

\subsection{Spatial and temporal variability of precipitation rates}

The ANN model was utilized to estimate gridded monthly precipitation sums, the maximum daily precipitation and the number of rainy days for each month with a horizontal resolution of $1 \mathrm{~km}^{2}$ for the period from 1989 to 2011 . The prominent features of the spatial, seasonal and interannual variability of modeled precipitation rates were analyzed and are highlighted below with emphasis on the winter- and summertype circulation. Therefore the mean precipitation sums for January and July are mapped in Fig. 7. To quantify the interannual variability, the coefficient of variation, defined as the ratio of the standard deviation by the mean precipitation sum, was calculated cellwise. Further, for a rough estimation of the precipitation intensity and frequency the percentage of the maximum daily precipitation of the monthly precipitation sum is given in Fig. 7. Since the number of rainy days highly 


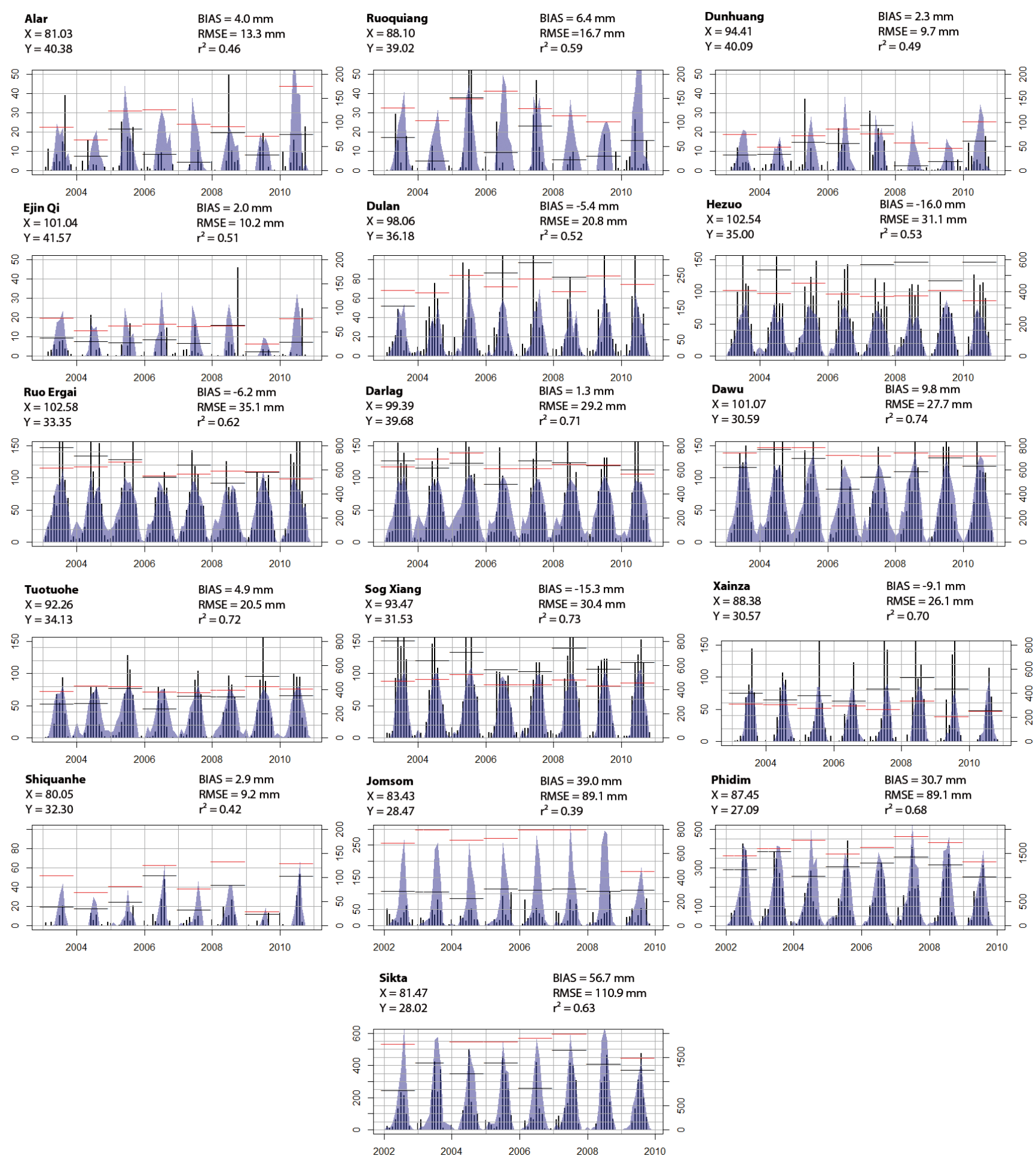

Figure 6. Observed (black bars) and modeled (polygons) monthly precipitation sums [mm month ${ }^{-1}$ ] (left $y$ axis) and observed (black lines) and modeled (red lines) annual precipitation sums [ $\mathrm{mm} \mathrm{a}^{-1}$ ] (right $y$ axis) for 16 stations of the evaluation data set. The scale of the $y$ axis is adapted to the maximum precipitation amount at each station. 

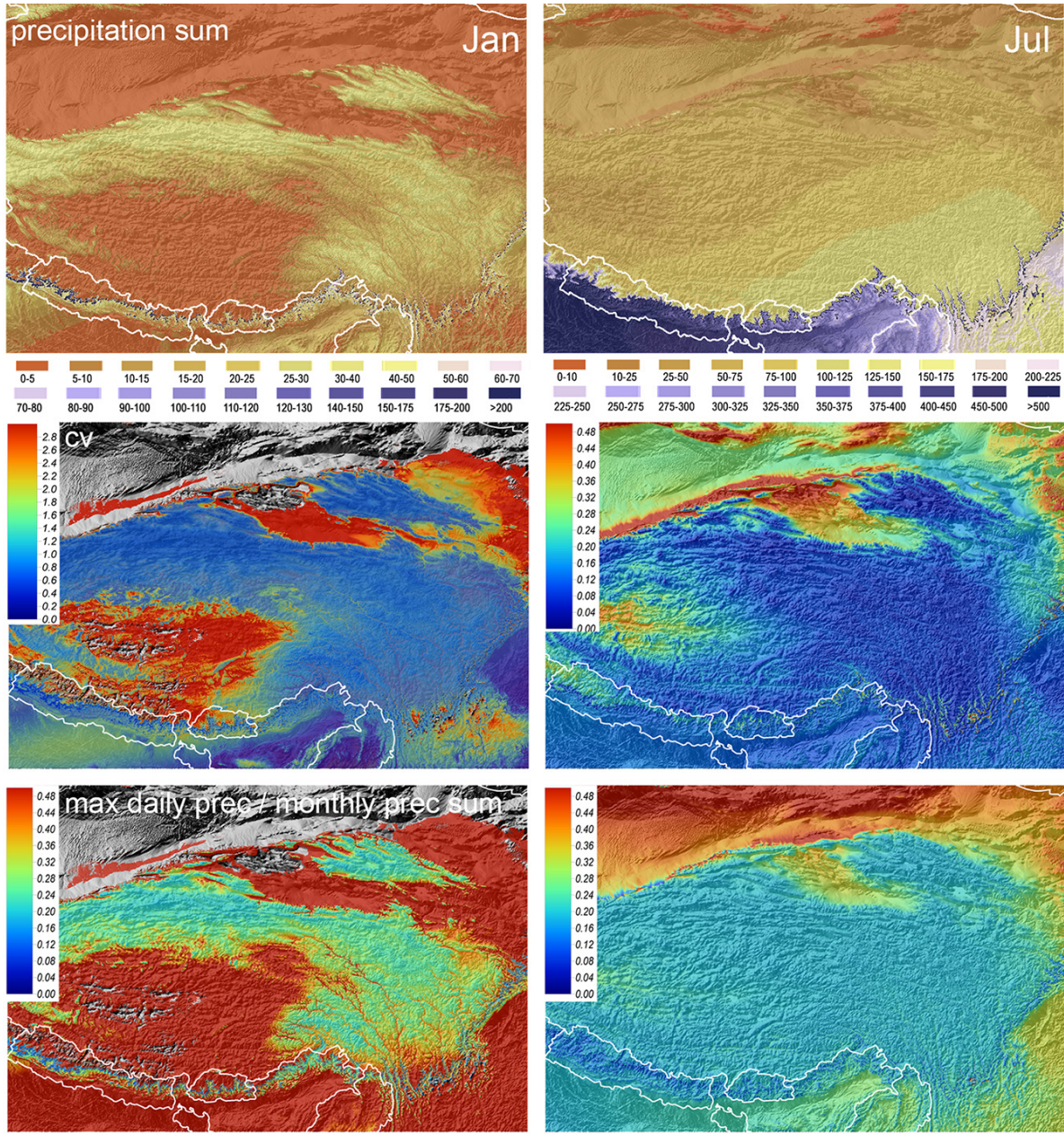

Figure 7. Mean monthly precipitation sum [mm] (top panels), coefficient of variation (middle panels) and the ratio of maximum daily precipitation and the monthly sum (bottom panels) for January (left panels) and July (right panels).

correlates with monthly precipitation sums and the maximum daily intensity, we resign to map this additional predictand variable.

As expected, the simulated large-scale precipitation distribution in the target area is mainly determined by the prevailing atmospheric modes. During winter season the circulation pattern is characterized by the Asiatic High in the boundary layer and the southward shift of the $200 \mathrm{hPa}$ jetstream. The target area is mainly dominated by dry conditions. Particularly for the Tarim Basin, no January precipitation was predicted for the entire period. Similarly, the lowlands of India and the Red Basin show monthly precipitation sums below $20 \mathrm{~mm}$. The Tibetan Plateau, especially the western part, which is located leeward of the Karakoram and Pamir mountains, receives mean monthly precipitation sums below $30 \mathrm{~mm}$ and shows a large interannual variability of precipitation rates $\left(c_{\mathrm{v}}>2\right)$. Meanwhile the Kunlun and Quilian mountains act as a barrier to the prevailing westerly flow. The uplift of advected air masses and the occasional passage of westerly disturbances result in considerable winter precipitation amounts. For January the mean precipitation sums at the western slopes of the mountain ranges reach more than $50 \mathrm{~mm}$; for the leeward slopes and the valley bottoms less than $20 \mathrm{~mm}$ is characteristic. The rainfall occurs reliably and steadily, the interannual variability is small, and the low ratio of maximum daily precipitation and the monthly sum indicates a temporally uniform precipitation distribution and the absence of extreme events (see Fig. 7). The maximum of January precipitation occurs at the western margin of the Himalayas due to a stronger southern branch of the $200 \mathrm{hPa}$ jetstream. The windward slopes receive up to $150 \mathrm{~mm}$ on average during January. The amounts of winter precipitation at the Himalayan slopes show a clear gradient from west to east. Like the Kunlun and Quilian Shan, the western Himalayas are characterized by comparably low variability in winter precipitation rates.

During spring, the pressure gradients over Asia decrease. The enhanced radiative forcing leads to occasional con- 


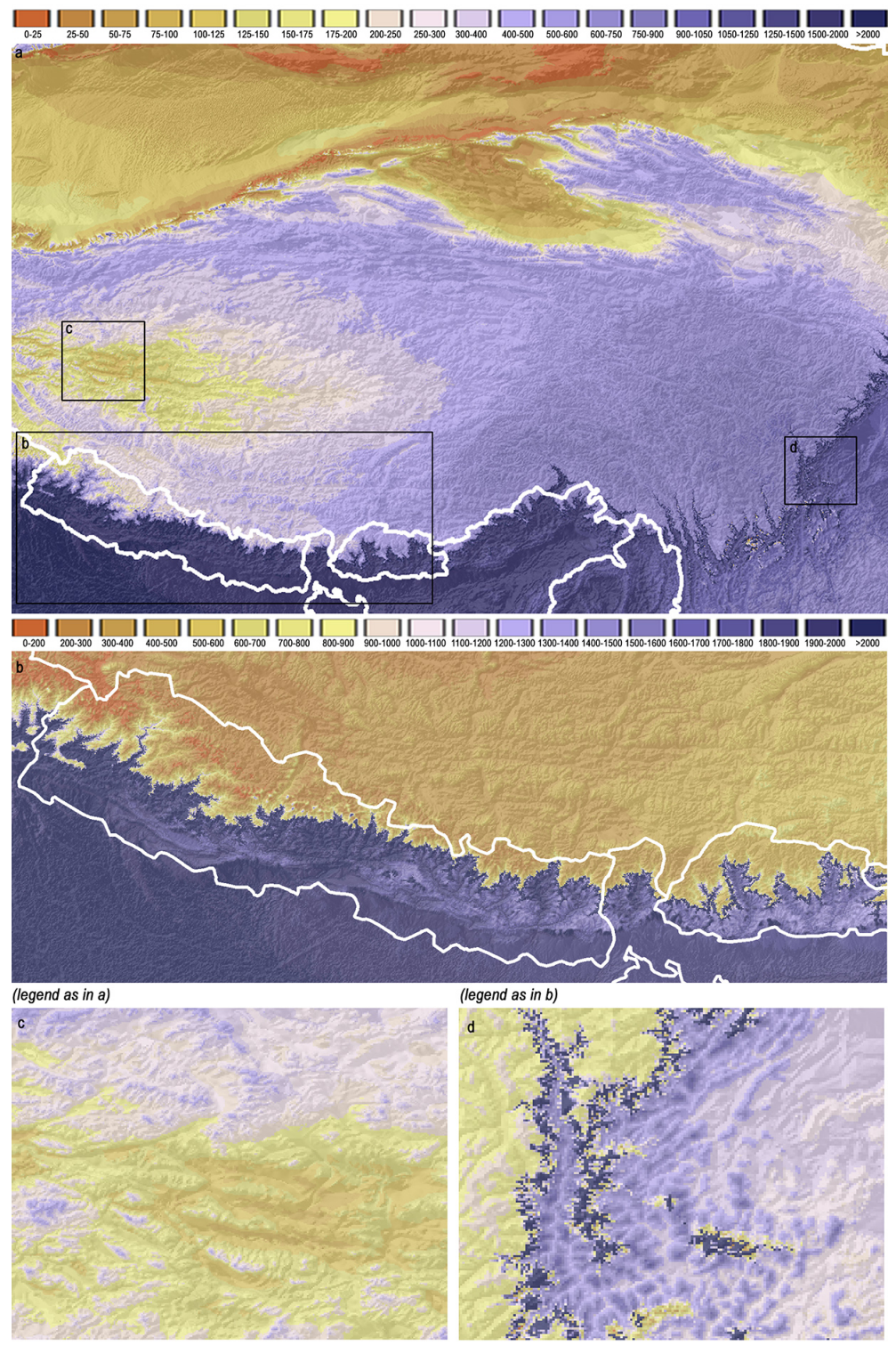

Figure 8. Modeled mean annual precipitation sums [mm] for the entire target domain (a) and enlargements of the central Himalayan Arc (b), the western Tibetan Plateau (c) and the margins of the Red Basin (d).

vective precipitation events, particularly over India and the southern Himalayan slopes, while the north of target area remains under dry conditions (figure not shown). In July the summer-type circulation pattern is fully established, the monsoonal flow leads to intense moisture fluxes into the study region. Particularly the Indus-Ganges Lowlands and the Himalayan slopes receive heavy rainfall, with mean monthly sums of partially more than $1000 \mathrm{~mm}$ at windward positions. Since the Indian Lowlands are only rudimentarily represented by our observations, the results of the approach for that particular subdomain should be considered less reliable. For the well-represented Himalayan slopes, the model results indicate the occurrence of two high precipita- tion bands, as observed by Bookhagen and Burbank (2006). The first discontinuous zone of high precipitation is located at the windward sites of the first orographic barrier of the outer Himalayas at elevations between 1500 and $2000 \mathrm{~m}$. A second band of high precipitation occurs south of the highest Himalayan peaks at elevations between 2000 and $2500 \mathrm{~m}$. The zones of maximal precipitation are followed by a sharp decrease above $4000 \mathrm{~m}$. Particularly for the southern Himalayan slopes, the precipitation distribution during summer results in a distinct differentiation of annual precipitation sums (see Fig. 8b). The variability of monsoonal precipitation at the Himalayan slopes is low, particularly for the eastern Himalayas, where $c_{\mathrm{v}}$ values below 0.1 were computed by 
the ANN model. The leeward regions of the Trans-Himalayas receive less than $90 \mathrm{~mm}$ average precipitation during July. Contemporaneously, the Red Basin is under the influence of the East Asian monsoon and receives precipitation amounts of more than $300 \mathrm{~mm}$ on average during July. For the windward slopes east of the Tibetan Plateau, monthly precipitation sums of up to $1000 \mathrm{~mm}$ were estimated. However, the depiction of annual precipitation sums for the eastern margin of the Tibetan Plateau shows a scattered precipitation distribution, which might indicate the appearance of statistical artifacts in that particular region. The interannual variability of monsoonal precipitation in the Red Basin was found to be low, with $c_{\mathrm{V}}$ values below 0.1 . The precipitation distribution over the Tibetan Plateau shows a clear east-west gradient during summer. The east of the plateau is penetrated by moist monsoonal air masses due to the meridional orientation of the Three River Gorges. This results in monthly precipitation sums of up to $150 \mathrm{~mm}$. The western part is situated leeward of the Himalayan and Karakoram mountain ranges and thus remains under dry conditions. For the valley bottoms, the monthly precipitation estimates amount to less than $20 \mathrm{~mm}$; for the elevated sites up to $50 \mathrm{~mm}$ was computed. This indicates a rather convective precipitation regime by implication of the diurnal mountain-valley circulation. The interannual variability is notably higher compared to advectiondominated regions such as the windward slopes of the main mountain ranges $\left(c_{\mathrm{V}}>0.4\right.$; see Fig. 7$)$. Likewise, the higher ratio of maximum daily precipitation and the monthly precipitation sum (partially $40 \%$ of the monthly precipitation amount fall within one day) indicates the occurrence of sporadic precipitation events. The Quilian Mountains receive higher summer precipitation amounts of more than $70 \mathrm{~mm}$ during July and mark the border of the East Asian monsoonal influence. The leeward slopes, the Tsaidam Depression in the southeast of the Quilian Shan, and the Tarim Basin are characterized by mean monthly precipitation sums below $20 \mathrm{~mm}$ and a considerably larger interannual variability with $c_{\mathrm{V}}$ values ranging from 0.3 to 0.5 . In the Tarim Basin the maximum of daily precipitation exceeds $50 \%$ of the monthly precipitation sum. This indicates the importance of autochthonous convective precipitation events for the northernmost part of the study region.

The estimated mean annual precipitation sums (Fig. 8) reach 1500 to $2000 \mathrm{~mm}$ in the lowlands of India and more than up to $4000 \mathrm{~mm}$ at the southern slopes of the central Himalayas. The Himalayan valleys, located north of the first orographic barriers of the monsoonal current, receive considerably reduced annual precipitation amounts on the order of 1200 to $1500 \mathrm{~mm}$ (Fig. 8b). The Indian Lowlands and the eastern Himalayas receive more than $80 \%$ of the annual rainfall during summer. For the western Himalayas the percentage of summer precipitation reaches barely $60 \%$ of the annual amount. The annual precipitation estimates for the Tibetan Plateau reveal a strong east-west gradient, with amounts below $100 \mathrm{~mm}$ in the far west and above $1000 \mathrm{~mm}$ in the monsoon-influenced eastern part. Particularly in western Tibet, the valley bottoms are characterized by arid conditions with annual precipitation sums below $100 \mathrm{~mm}$, while the elevated sites reach values of up to $350 \mathrm{~mm}$ (Fig. 8c). The precipitation estimates for the Kunlun Mountains amount to approximately 400 to $600 \mathrm{~mm}$, with maximum values in the far west due to an enhanced winter precipitation (DJF), which reaches up to $50 \%$ of the annual precipitation sum. The annual precipitation over the Quilian Shan reaches 500 to $600 \mathrm{~mm}$ with highest values at the stronger monsooninfluenced east-facing slopes. The Tarim Basin is characterized by dry conditions throughout the year; the annual precipitation sum amounts to less than $80 \mathrm{~mm}$. The convective precipitation during summer amounts to almost $90 \%$ of the annual sum.

\subsection{Sensitivity analysis for large-scale atmospheric and topographic predictor variables}

In comparison to linear models, the complex structure of the ANN does not directly reveal physically interpretable input-output relationships. Thus ANNs are often mentioned as black-box models (Schönwiese et al., 2010). For the identification of the particular synoptic- and local-scale processes leading to a spatial and temporal precipitation variability in the target area, a local sensitivity analysis was conducted and is exemplarily illustrated for four locations which represent varying precipitation regimes in the study region (Fig. 9). Nearby locations in general show similar results of the sensitivity analysis. In each case one predictor variable was chosen as a running variable, taking values between the 0.1 and 1.0 percentiles of the learning sample, while all other predictors were set to constant values. For the assessment of the model sensitivity to altering large-scale atmospheric predictor variables (Fig. 9a), all predictors (apart from the considered running variable) were set to their mean values (which is 0 for normalized values). The predicted precipitation amounts display the response of the ANN model, i.e., the modeled precipitation amounts $\left[\mathrm{mm} \mathrm{month}^{-1}\right]$, to modified values of the considered predictor variables and provide an insight into the internal model structure. For the assessment of the response of the ANN model to altering topographic characteristics of the underlying surface, two sensitivity experiments under different large-scale atmospheric conditions were conducted. In order to investigate the model sensitivity to topographic characteristics under dry conditions (Fig. 9b), the relative humidity at the 500 and $200 \mathrm{hPa}$ level was set to $0 \%$ and the scores of the first EOF were set to the minimum value, representing a typical winter type circulation pattern. All other predictor variables were set to their mean values. For an assessment of the model sensitivity under moist conditions, the relative humidity was set to $100 \%$ and the EOF1 scores were set to maximum, as characteristic for the summer circulation type (Fig. 9c). Furthermore, a generalized sensitivity analysis for the maximum daily precipitation amounts 
Sikta $\quad X=81.47^{\circ} \quad Y=28.02^{\circ}$
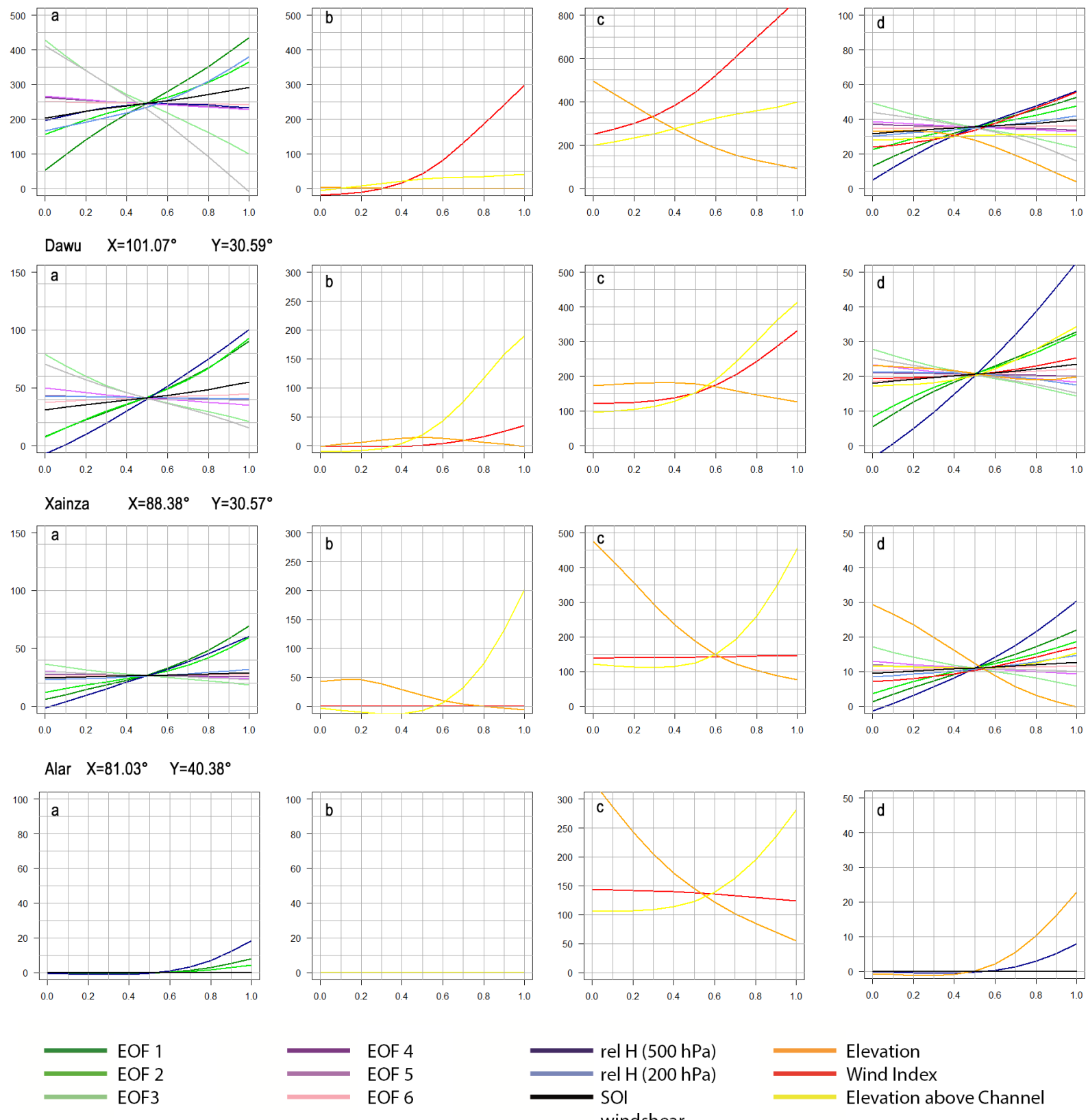

Elevation

Wind Index

Elevation above Channel

Figure 9. Sensitivity analysis of the ANN model for the atmospheric and topographic predictor variables at selected locations. Values are in millimeters. (a) Sensitivity of the modeled monthly precipitation sums to altering values of large-scale atmospheric predictor variables. (b) Sensitivity of monthly precipitation sums to topographic predictor variables under dry conditions. (c) Sensitivity of monthly precipitation sums to topographic predictor variables under moist conditions. (d) Generalized sensitivity analysis of maximum daily precipitation amounts.

was conducted for both atmospheric and topographic precipitation amounts (Fig. 9d). Therefore all predictors (beside of the running variable) were set to their mean values.

The ANN signal of each predictor variable for the monthly precipitation sums and the maximum daily precipitation amount is plotted in Fig. 9. The station Sikta, situated near the southern Nepali border, represents the monsoonal cli- mate of the Indian Lowlands and the slopes of the Himalayas. The first EOF (indicating the pressure gradient between the Asian continent and the Indian Ocean) and the relative humidity (especially at $200 \mathrm{hPa}$ ) were found to be the crucial large-scale predictors for the observed precipitation rates. A strong positive pressure gradient during summer intensifies the monsoonal circulation and leads to enhanced precip- 
itation rates over the Indus-Ganges Lowlands and the Himalayan Arc. The positive response to increasing values of second EOF scores (which are negatively correlated with the SOI) indicates a positive implication of El Niño events for the monsoonal precipitation amounts at first sight. However a further correlation analysis of the predictor variables reveals a strong negative relationship $(r>0.5, p=0.95)$ of the EOF2 scores and the $500 \mathrm{hPa}$ relative humidity during summer for all stations located in the Indian Lowlands and at the southern Himalayan slopes. For other regions of the target area, no significant correlation could be identified. This indicates a decreased moisture flux into the target area during El Niño events, which is sufficiently captured by the assimilated ERA-Interim reanalysis. Particularly for the 2009 monsoon season, the relative humidity fields of the reanalysis show a considerably negative anomaly over India and the Himalayas (not shown). In combination with a slight negative anomaly of the large-scale pressure gradients, this results in reduced precipitation rates predicted by the ANN model (see Fig. 6). The negative response to increasing values of the wind shear has to be interpreted with regard to the annual shift of the $200 \mathrm{hPa}$ jetstream. While the windshear over India during monsoon season is comparably low, the winter circulation pattern is characterized by high wind speeds in the upper troposphere. Although a southward shift of the jetstream leads to the occasional passage of westerly disturbances, the winter season is mainly dominated by dry synoptic conditions. For the local-scale precipitation distribution, the wind-effect parameter could be identified as the major topographic predictor variable for the Himalayan slopes, resulting in a considerable topographic differentiation of the precipitation estimates. The model particularly shows a distinct response to the wind-effect parameter under moist conditions; however, even under dry atmospheric circumstances, the estimates of monthly precipitation amounts show higher values at windward slopes (Fig. 9b and c). Likewise, the sensitivity analysis indicates that the topographic differentiation of maximum daily precipitation rates for the southern $\mathrm{Hi}-$ malayan slopes is primarily determined by the wind-effect parameter (Fig. 9d). The negative response of increasing elevations implies a sharp precipitation decrease above $4000 \mathrm{~m}$. The sensitivity analysis for Dawu (located on the eastern Tibetan Plateau) shows a similar response for most of the synoptic and topographic predictor variables. However, in comparison with the southern Himalayan slopes, the precipitation estimates show a clear positive response to increasing values of the relative elevation above the nearest channel network under both moist and dry large-scale atmospheric conditions. Particularly for the maximum daily precipitation amounts, the response of the ANN model to variations in $Z_{\text {rel }}$ was found to be considerably larger than the influence of the wind effect. This indicates the importance of convective precipitation events for the spatial precipitation distribution over the eastern Tibetan Plateau and especially for the generation of intense precipitation events. The fact that the model dis- tinctly responses to increasing values of the relative elevation, even under dry atmospheric conditions, might indicate the importance of local water recycling for the precipitation formation on the Tibetan Plateau as suggested, for example, by Kurita and Yamada (2008) and Yang et al. (2007). For the location of Xainza (western Tibetan Plateau) the ANN response to variations in the wind effect seems to be negligible. Elevation and relative elevation above the channel network were detected as the most influential predictors for the spatial precipitation distribution, indicating a rather convective precipitation regime over the western Tibetan Plateau. Again, the modeled monthly precipitation amounts increase with rising values of relative elevation under moist and dry large-scale atmospheric conditions. The sensitivity analysis for Alar, located in the arid Tarim Basin, mainly reveals a certain response of the ANN model to variations in moisture fluxes into the Tarim basin, represented by the $500 \mathrm{hPa}$ relative humidity of the ERA-Interim reanalysis. A slight positive response to increased EOF1 scores is most likely due to isochronous development of the summer monsoon circulation pattern and the occurrence of convective precipitation events and should not be interpreted as a monsoonal influence. Under dry atmospheric conditions, the precipitation distribution over the homogenous Tarim Basin appears to be rather unaffected by varying topographic settings. High values of relative humidity and the first EOF scores lead to distinct topographic differentiation of monthly precipitation rates, comparable with the western Tibetan Plateau, which is dominated by a convective precipitation regime. However, it should be mentioned that such high values of relative humidity actually do not occur over the central Asian deserts.

\section{Conclusions and outlook}

The presented ANN-based downscaling approach sufficiently captures the large- and local-scale variations in the precipitation distribution in the highly structured target area. By means of the integration of physically based terrain parameters, the approach addresses particular local-scale atmospheric processes and enables the statistical downscaling of fully distributed precipitation fields in mountainous environments.

Especially for the monsoon-dominated precipitation regimes of the Indus-Ganges Lowlands, the Himalayan slopes and the Red Basin the approach explains up to $70 \%$ of the variability of monthly precipitation sums. However, for the Kunlun and Quilian mountains, where precipitation occurs mainly due to western circulation patterns, and for the convection-dominated regions, such as the western Tibetan Plateau and the Tarim Basin, the results are less reliable $\left(r^{2}=0.5\right)$.

The trained ANN model stands out due to its nonlinearity and its ability to capture the interactions of related largescale atmospheric and topographic predictor variables and 
facilitates the consideration of varying precipitation-forming processes in different subregions of the modeling domain. A subsequent local sensitivity analysis can reveal the influence of specific predictor variables on the ANN output. While the large-scale spatial variations and the seasonal cycle of the monthly precipitation amounts were found to be determined by varying circulation modes and moisture fluxes, as represented by the ERA-Interim reanalysis, the local-scale precipitation distribution was found to be highly influenced by topographic characteristics. However, the impact of the topographic parameters highly depends on the large-scale climatic regimes. Complex artificial neural networks are effective modeling tools precisely for that reason, particularly in comparison with linear regression models which suggest a constant statistical relationship of predictor and predictand variables for the entire target area. While windward and leeward positions were identified as the major topographic predictor for the local-scale spatial precipitation variations in the monsoon-dominated regions of India and the Himalayas, the rather convection-dominated precipitation regimes of the western Tibetan Plateau appear to be mainly influenced by the relative elevation above the channel network and the accompanying diurnal mountain-valley circulation.

The spatial resolution of the modeled precipitation rates of $1 \mathrm{~km}^{2}$ is auspicious for climate impact studies, e.g., for the analysis of climate-sensitive ecosystems and hydrological regimes. However the focus of the presented study on monthly precipitation estimates still does not satisfy the requirements of several geoscientific modeling approaches. Hence, further research needs to be done to generate spatially and temporally high resolution precipitation estimates. Since the terrain-induced precipitation-forming processes show large temporal variability due to varying mesoscale atmospheric characteristics, the assessment of daily precipitation rates remains challenging. Böhner (1996) illustrates that the representation of precipitation amounts for monthly observations in central Asia remains below $200 \mathrm{~km}$. This is particularly valid for the convection-dominated regions of the target area and indicates the heterogeneity of precipitation observations in complex terrain. The daily precipitation amounts in the study region are determined by mesoscale atmospheric processes, such as the passage of tropical and westerly disturbances or the development of convective clusters, which are not sufficiently represented by limited resolution climate models or reanalysis products. The mesoscale atmospheric patterns, however, are crucial for the identification of the flow direction and the moisture fluxes on a daily timescale. This further increases atmospheric heterogeneity in mountainous regions and impedes the statistical analysis of interactions between the atmospheric circulation and the underlying topographic characteristics. State-of-the-art dynamical downscaling models can be effective alternatives for the simulation of mesoscale atmospheric processes, but due to their high computational demands and their requirements for high-quality input data, most studies focus on a limited spatial domain or time frame. So far the WRF-based High Asia Refined analysis (Maussion et al., 2014) is the only data set known to the authors which adequately captures the mesoscale climatic variability for the entire target region of this study for the reasonable period from 2001 to 2011 . Although the resolution of $10 \mathrm{~km}$ still does not satisfy the needs of many climate impact investigations, the data set could provide improved free-atmospheric predictor variables for statistical downscaling applications. The combination of dynamical downscaling and the presented statistical approach appears to be auspicious for the analysis of mesoscale atmospheric conditions and its modification due to local-scale topographic characteristics and should be considered for further research.

Acknowledgements. The ERA-Interim reanalysis fields were freely provided by the ECMWF. We appreciate the supply of daily meteorological observations by the Department of Hydrology and Meteorology (Kathmandu, Nepal) and the Chinese Meteorological Administration (Beijing, China). The study was funded by the Federal Ministry of Education and Research (Berlin, Germany) in the context of the project CLASH (Climate variability and landscape dynamics in Southeast-Tibet and the eastern Himalaya during the late Holocene reconstructed from tree rings, soils and climate modeling).

Edited by: V. Lucarini

\section{References}

Akhtar, M., Ahmad, N., and Booij, M. J.: The impact of climate change on the water resources of Hindukush-KarakorumHimalaya region under different glacier coverage scenarios, J. Hydrol., 355, 148-163, doi:10.1016/j.jhydrol.2008.03.015, 2008.

Bao, X. and Zhang, F.: Evaluation of NCEP/CFSR, NCEP/NCAR, ERA-Interim and ERA-40 Reanalysis Datasets against Independent Sounding Observations over the Tibetan Plateau, J. Climate, 26, 206-214, doi:10.1175/JCLI-D-12-00056.1, 2012.

Barros, A. P., Joshi, M., Putkonen, J., and Burbank, D. W.: A study of the 1999 monsoon rainfall in a mountainous region in central Nepal using TRMM products and rain gauge observations, Geophys. Res. Lett., 27, 3683-3686, doi:10.1029/2000GL011827, 2000.

Barry, R. G.: Recent advances in mountain climate research, Theor. Appl. Climatol., 110, 549-553, doi:10.1007/s00704-012-0695-x, 2012.

Basheer, I. A. and Hajmeer, M.: Artificial neural networks: fundamentals, computing, design, and application, J. Microbiol. Meth., 43, 3-31, 2000.

Berrisford, P., Dee, D., Fielding, K., Fuentes, M., Kallberg, P., Kobayashi, S., and Uppala, S.: The ERA-Interim Archive, ERA report series [online] available at: http://www.ecmwf. int/publications/library/do/references/list/782009 (last access: 15 January 2013), 2009.

Böhner, J.: Säkulare Klimaschwankungen und rezente Klimatrends Zentral- und Hochasiens, Goltze, Göttingen, 1996. 
Böhner, J.: General climatic controls and topoclimatic variations in Central and High Asia, Boreas, 35, 279-295, doi:10.1080/03009480500456073, 2006.

Böhner, J. and Antonić, O.: Chapter 8 Land-Surface Parameters Specific to Topo-Climatology, in: Developments in Soil Science, Vol. 33, edited by: Hengl, T. and Reuter, H. I., Elsevier, available at: http://www.sciencedirect.com/science/article/ pii/S0166248108000081, last access: 15 January 2013, 195-226, 2009.

Bookhagen, B. and Burbank, D. W.: Topography, relief, and TRMM-derived rainfall variations along the Himalaya, Geophys. Res. Lett., 33, L08405, doi:10.1029/2006GL026037, 2006.

Buishand, T. A.: Some methods for testing the homogeneity of rainfall records, J. Hydrol., 58, 11-27, 1982.

Chattopadhyay, S.: Feed forward Artificial Neural Network model to predict the average summer-monsoon rainfall in India, Acta Geophys., 55, 369-382, doi:10.2478/s11600-007-0020-8, 2007.

Chen, F., Liu, Y., Liu, Q., and Li, X.: Spatial downscaling of TRMM 3B43 precipitation considering spatial heterogeneity, Int. J. Remote Sens., 35, 3074-3093, doi:10.1080/01431161.2014.902550, 2014.

Corbosiero, K. L. and Molinari, J.: The Effects of Vertical Wind Shear on the Distribution of Convection in Tropical Cyclones, Mon. Weather Rev., 130, 2110-2123, doi:10.1175/15200493(2002)130<2110:TEOVWS>2.0.CO;2, 2002.

Coulibaly, P., Dibike, Y. B., and Anctil, F.: Downscaling Precipitation and Temperature with Temporal Neural Networks, J. Hydrometeorol., 6, 483-496, doi:10.1175/JHM409.1, 2005.

Daly, C., Neilson, R. P., and Phillips, D. L.: A StatisticalTopographic Model for Mapping Climatological Precipitation over Mountainous Terrain, J. Appl. Meteorol., 33, 140-158, doi:10.1175/1520-0450(1994)033<0140:ASTMFM>2.0.CO;2, 1994.

Dawson, C. W. and Wilby, R. L.: Hydrological modelling using artificial neural networks, Prog. Phys. Geogr., 25, 80-108, doi:10.1177/030913330102500104, 2001.

Dee, D. P., Uppala, S. M., Simmons, A. J., Berrisford, P., Poli, P., Kobayashi, S., Andrae, U., Balmaseda, M. A., Balsamo, G., and Bauer, P.: The ERA-Interim reanalysis: Configuration and performance of the data assimilation system, Q. J. Roy. Meteorol. Soc., 137, 553-597, 2011.

Dibike, Y. B. and Coulibaly, P.: Temporal neural networks for downscaling climate variability and extremes, Neural Networks, 19, 135-144, doi:10.1016/j.neunet.2006.01.003, 2006.

Dimri, A. P., Yasunari, T., Wiltshire, A., Kumar, P., Mathison, C., Ridley, J., and Jacob, D.: Application of regional climate models to the Indian winter monsoon over the western Himalayas, Sci. Total Environ., 468-469 doi:10.1016/j.scitotenv.2013.01.040, 2013.

Domrös, M.: The Climate of China, Springer, Berlin, 1988.

Farr, T. G., Rosen, P. A., Caro, E., Crippen, R., Duren, R., Hensley, S., Kobrick, M., Paller, M., Rodriguez, E., and Roth, L.: The shuttle radar topography mission, Rev. Geophys., 45, RG2004, doi:10.1029/2005RG000183, 2007.

Filippi, L., Palazzi, E., Von Hardenberg, J., and Provenzale, A.: Multidecadal Variations in the Relationship between the NAO and Winter Precipitation in the Hindu Kush-Karakoram, J. Climate, 27, 7890-7902, doi:10.1175/JCLI-D-14-00286.1, 2014.
Flohn, H. : Recent investigations on the climatogenetic role of the Qinghai-Plateau: Now and during the late Cenozoik, in: Reports of the Qinghai-Xizang (Tibet) Plateau, edited by: Hövermann, J. and Wang, W., Science Press, Beijing, 112-139, 1987.

Frank, W. M. and Ritchie, E. A.: Effects of Vertical Wind Shear on the Intensity and Structure of Numerically Simulated Hurricanes, Mon. Weather Rev., 129, 2249-2269, doi:10.1175/15200493(2001)129<2249:EOVWSO>2.0.CO;2, 2001.

Gao, L., Bernhardt, M., and Schulz, K.: Elevation correction of ERA-Interim temperature data in complex terrain, Hydrol. Earth Syst. Sci., 16, 4661-4673, doi:10.5194/hess-16-46612012, 2012.

Gerlitz, L.: Using fuzzyfied regression trees for statistical downscaling and regionalization of near surface temperatures in complex terrain, Theor. Appl. Climatol., doi:10.1007/s00704-014-1285-x, in press, 2014.

Gerlitz, L., Conrad, O., Thomas, A., and Bhner, J.: Warming patterns over the Tibetan Plateau and adjacent lowlands derived from elevation- and biascorrected ERA-Interim data, Clim. Res., 58, 235-246, doi:10.3354/cr01193, 2014.

Guan, H., Hsu, H.-H., Makhnin, O., Xie, H., and Wilson, J. L.: Examination of selected atmospheric and orographic effects on monthly precipitation of Taiwan using the ASOADeK model, Int. J. Climatol., 29, 1171-1181, doi:10.1002/joc.1762, 2009.

Günther, F. and Fritsch, S.: neuralnet: Training of neural networks, R Journal, 2, 30-38, 2010.

Hannachi, A., Jolliffe, I. T., Stephenson, D. B., and Trendafilov, N.: In search of simple structures in climate: simplifying EOFs, Int. J. Climatol., 26, 7-28, doi:10.1002/joc.1243, 2006.

Hannachi, A., Jolliffe, I. T., and Stephenson, D. B.: Empirical orthogonal functions and related techniques in atmospheric science: A review, Int. J. Climatol., 27, 1119-1152, doi:10.1002/joc.1499, 2007.

Hecht-Nielsen, R.: Theory of the backpropagation neural network, in: vol. 1, International Joint Conference on Neural Networks IJCNN, San Diego, 593-605, 1989.

Immerzeel, W. W. and Bierkens, M. F. P.: Seasonal prediction of monsoon rainfall in three Asian river basins: the importance of snow cover on the Tibetan Plateau, Int. J. Climatol., 30, 18351842, doi:10.1002/joc.2033, 2010.

Jain, A. and Kumar, A. M.: Hybrid neural network models for hydrologic time series forecasting, Appl. Soft Comput., 7, 585-592, doi:10.1016/j.asoc.2006.03.002, 2007.

Jin-Huan, Z. H. U., Shu-Po, M. A., Han, Z. O. U., Li-Bo, Z., and Peng, L. I.: Evaluation of reanalysis products with in situ GPS sounding observations in the Eastern Himalayas, Atmos. Ocean. Sci. Lett., 7, 17-22, 2013.

Kirono, D. G. C., Tapper, N. J., and McBride, J. L.: Documenting Indonesian Rainfall in the 1997/1998 El Niño Event, Phys. Geogr., 20, 422-435, doi:10.1080/02723646.1999.10642687, 1999.

Kumar, K. K., Rajagopalan, B., Cane, M. A.: On the weakening relationship between the indian monsoon and ENSO, Science, 284, 2156-2159, 1999.

Kurita, N. and Yamada, H.: The Role of Local Moisture Recycling Evaluated Using Stable Isotope Data from over the Middle of the Tibetan Plateau during the Monsoon Season, J. Hydrometeorol., 9, 760-775, doi:10.1175/2007JHM945.1, 2008.

Li, C. and Yanai, M.: The Onset and Interannual Variability of the Asian Summer Monsoon in Relation to Land-Sea 
Thermal Contrast, J. Climate, 9, 358-375, doi:10.1175/15200442(1996)009<0358:TOAIVO>2.0.CO;2, 1996.

Mall, R. K., Singh, R., Gupta, A., Srinivasan, G., and Rathore, L. S.: Impact of Climate Change on Indian Agriculture: A Review, Climatic Change, 78, 445-478, doi:10.1007/s 10584-005-9042-x, 2006.

Maraun, D., Wetterhall, F., Ireson, A. M., Chandler, R. E., Kendon, E. J., Widmann, M., Brienen, S., Rust, H. W., Sauter, T., Themeß1, M., Venema V. K. C., Chun K. P., Goodess, C. M., Jones R. G., Onof, C., Vrac, M., and Thiele-Eich, I.: Precipitation downscaling under climate change: recent developments to bridge the gap between dynamical models and the end user, Rev. Geophys., 48, RG3003, doi:10.1029/2009RG000314, 2010.

Matthews, R. B., Kropff, M. J., Horie, T., and Bachelet, D.: Simulating the impact of climate change on rice production in Asia and evaluating options for adaptation, Agr. Syst., 54, 399-425, doi:10.1016/S0308-521X(95)00060-I, 1997.

Maussion, F., Scherer, D., Mölg, T., Collier, E., Curio, J., and Finkelnburg, R.: Precipitation Seasonality and Variability over the Tibetan Plateau as Resolved by the High Asia Reanalysis, J. Climate, 27, 1910-1927, doi:10.1175/JCLI-D-13-00282.1, 2014.

Mekanik, F., Imteaz, M. A., Gato-Trinidad, S., and Elmahdi, A.: Multiple regression and Artificial Neural Network for long-term rainfall forecasting using large scale climate modes, J. Hydrol., 503, 11-21, doi:10.1016/j.jhydrol.2013.08.035, 2013.

Özesmi, S. L. and Özesmi, U.: An artificial neural network approach to spatial habitat modelling with interspecific interaction, Ecol. Model., 116, 15-31, doi:10.1016/S0304-3800(98)00149-5, 1999.

Parth Sarthi, P., Agrawal, A., and Rana, A.: Possible future changes in cyclonic storms in the Bay of Bengal, India under warmer climate, Int. J. Climatol., doi:10.1002/joc.4053, in press, 2014.

Peings, Y. and Douville, H.: Influence of the Eurasian snow cover on the Indian summer monsoon variability in observed climatologies and CMIP3 simulations, Clim. Dynam., 34, 643-660, doi:10.1007/s00382-009-0565-0, 2010.

Pokhrel, S., Chaudhari, H. S., Saha, S. K., Dhakate, A., Yadav, R. K., Salunke, K., Mahapatra, S., and Rao, S. A.: ENSO, IOD and Indian Summer Monsoon in NCEP climate forecast system, Clim. Dynam., 39, 2143-2165, doi:10.1007/s00382-012-1349-5, 2012.

Preethi, B., Revadekar, J. V., and Kripalani, R. H.: Anomalous behaviour of the Indian summer monsoon 2009, J. Earth Syst. Sci., 120, 783-794, doi:10.1007/s12040-011-0112-3, 2011.

Prodhomme, C., Terray, P., Masson, S., Boschat, G., and Izumo, T.: Oceanic factors controlling the Indian summer monsoon onset in a coupled model, Clim. Dynam., 44, 977-1002, doi:10.1007/s00382-014-2200-y, 2015.

Ranjan Nayak, D., Mahapatra, A., and Mishra, P.: A Survey on Rainfall Prediction using Artificial Neural Network, Int. J. Comput. Appl., 72, 32-40, doi:10.5120/12580-9217, 2013.

Romatschke, U., Medina, S., and Houze, R. A.: Regional, Seasonal, and Diurnal Variations of Extreme Convection in the South Asian Region, J. Climate, 23, 419-439, doi:10.1175/2009JCLI3140.1, 2010.

Sankar, S., Kumar, M. R. R., and Reason, C.: On the relative roles of El Nino and Indian Ocean Dipole events on the Monsoon Onset over Kerala, Theor. Appl. Climatol., 103, 359-374, doi:10.1007/s00704-010-0306-7, 2011.
Sauter, T. and Venema, V.: Natural Three-Dimensional Predictor Domains for Statistical Precipitation Downscaling, J. Climate, 24, 6132-6145, doi:10.1175/2011JCLI4155.1, 2011.

Sauter, T., Schneider, C., Kilian, R., and Moritz, M.: Simulation and analysis of runoff from a partly glaciated meso-scale catchment area in Patagonia using an artificial neural network, Hydrol. Process., 23, 1019-1030, doi:10.1002/hyp.7210, 2009.

Schönwiese, C.-D., Walter, A., and Brinckmann, S.: Statistical assessments of anthropogenic and natural global climate forcing. An update, Meteorol. Z., 19, 3-10, doi:10.1127/09412948/2010/0421, 2010.

Schoof, J. T.: Statistical Downscaling in Climatology, Geogr. Compass, 7, 249-265, doi:10.1111/gec3.12036, 2013.

Schoof, J. T. and Pryor, S. C.: Downscaling temperature and precipitation: a comparison of regression-based methods and artificial neural networks, Int. J. Climatol., 21, 773-790, doi:10.1002/joc.655, 2001.

Shrestha, D., Singh, P., and Nakamura, K.: Spatiotemporal variation of rainfall over the central Himalayan region revealed by TRMM Precipitation Radar, J. Geophys. Res., 117, D22106, doi:10.1029/2012JD018140, 2012.

Shrestha, M. L.: Interannual variation of summer monsoon rainfall over Nepal and its relation to Southern Oscillation Index, Meteorol. Atmos. Phys., 75, 21-28, doi:10.1007/s007030070012, 2000.

Shukla, R. P., Tripathi, K. C., Pandey, A. C., and Das, I. M. L.: Prediction of Indian summer monsoon rainfall using Niño indices: A neural network approach, Atmos. Res., 102, 99-109, doi:10.1016/j.atmosres.2011.06.013, 2011.

Sigdel, M. and Ikeda, M.: Summer Monsoon Rainfall over Nepal Related with Large-Scale Atmospheric Circulations, J. Earth Sci. Clim. Change, 3.2, 1000112, doi:10.4172/2157-7617.1000112, 2012.

Singh, P. and Borah, B.: Indian summer monsoon rainfall prediction using artificial neural network, Stoch. Environ. Res. Risk Assess., 27, 1585-1599, doi:10.1007/s00477-013-0695-0, 2013.

Slingo, J. M. and Annamalai, H.: 1997: The El Niño of the Century and the Response of the Indian Summer Monsoon, Mon. Weather Rev., 128, 1778-1797, doi:10.1175/15200493(2000)128<1778:TENOOT>2.0.CO;2, 2000.

Suprit, K. and Shankar, D.: Resolving orographic rainfall on the Indian west coast, Int. J. Climatol., 28, 643-657, doi:10.1002/joc.1566, 2008.

Tomassetti, B., Verdecchia, M., and Giorgi, F.: NN5: A neural network based approach for the downscaling of precipitation fields - Model description and preliminary results, J. Hydrol., 367, 1426, doi:10.1016/j.jhydrol.2008.12.017, 2009.

Wang, A. and Zeng, X.: Evaluation of multireanalysis products with in situ observations over the Tibetan Plateau, J. Geophys. Res., 117, D05102, doi:10.1029/2011JD016553, 2012.

Wang, D., Xie, Q., Du, Y., Wang, W., and Chen, J.: The 1997-1998 warm event in the South China Sea, Chin. Sci. Bull., 47, 12211227, doi:10.1007/BF02907614, 2002.

Wang, H. and He, S.: Weakening relationship between East Asian winter monsoon and ENSO after mid-1970s, Chin. Sci. Bull., 57, 3535-3540, doi:10.1007/s11434-012-5285-x, 2012.

Wingo, M. T. and Cecil, D. J.: Effects of Vertical Wind Shear on Tropical Cyclone Precipitation, Mon. Weather Rev., 138, 645662, doi:10.1175/2009MWR2921.1, 2009. 
Wulf, H., Bookhagen, B., and Scherler, D.: Seasonal precipitation gradients and their impact on fluvial sediment flux in the Northwest Himalaya, Geomorphology, 118, 13-21, doi:10.1016/j.geomorph.2009.12.003, 2010.

Xu, Z. X., Chen, Y. N., and Li, J. Y.: Impact of climate change on water resources in the Tarim River basin, Water Resour. Manage., $18,439-458,2004$.
Yang, M., Yao, T., Gou, X., and Tang, H.: Water Recycling between the Land Surface and Atmosphere on the Northern Tibetan Plateau: A Case Study at Flat Observation Sites, Arct. Antarct. Alp. Res., 39, 694-698, 2007. 